\title{
Palladium-Catalyzed Asymmetric Allylic Alkylation Strategies for the Synthesis of Acyclic Tetrasubstituted Stereocenters
}

\author{
Barry M. Trost* (1) \\ Johnathan E. Schultz \\ Department of Chemistry, Stanford University, 335 Campus \\ Drive, Stanford, CA 94305, USA \\ bmtrost@stanford.edu \\ schultz2@stanford.edu \\ Published as part of the 50 Years SYNTHESIS - Golden Anniversary \\ Issue
}

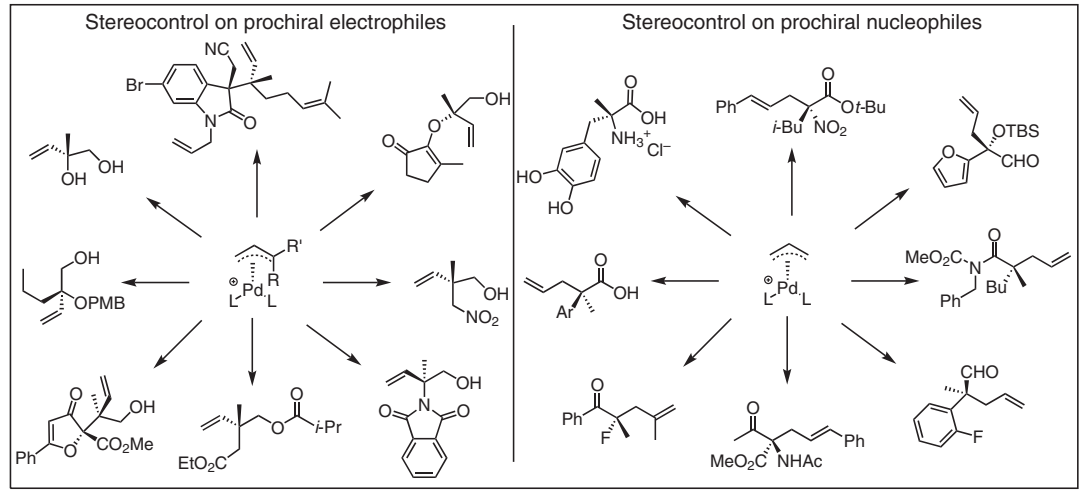

Received: 23.10.2018

Accepted: 24.10 .2018

Published online: 05.12 .2018

DOI: 10.1055/s-0037-1610386; Art ID: ss-2018-z0713-r

License terms: cc)

\begin{abstract}
Over the past 20 years, the asymmetric synthesis of acyclic tetrasubstituted stereocenters by Pd-catalyzed asymmetric allylic alkylation (Pd-AAA) strategies has seen considerable growth. Despite the inherent difficulty in accessing acyclic tetrasubstituted stereocenters, creative approaches toward this problem have resulted in high stereoinduction on both electrophilic and nucleophilic reaction partners. Much of this chemistry has paved the way for unique solutions in Mo-, Ir-, and Rh-AAA, with many complimentary methods arising due to the unique regiochemical outcomes of AAA outside of Pd catalysis.

1 Introduction

Stereocontrol on Prochiral Electrophiles

Stereocontrol on Prochiral Nucleophiles

Temporary Cyclic Pronucleophiles

Allylic Alkylation with Other Metals

Conclusions and Outlook
\end{abstract}

Key words allylic alkylation, acyclic stereocontrol, tertiary alcohols, $\alpha$ tertiary amines, quaternary carbon stereocenters

\section{Introduction}

Palladium-catalyzed asymmetric allylic alkylation (PdAAA) stands as a unique reaction due to the high number of stereocenters that may be created by this process. ${ }^{1}$ Arguably, few transition-metal-catalyzed reactions offer the synthetic chemist the ability to form $\mathrm{C}-\mathrm{C}, \mathrm{C}-\mathrm{N}, \mathrm{C}-\mathrm{O}, \mathrm{C}-\mathrm{F}$, and $\mathrm{C}-\mathrm{S}$ bonds by such a variety of mechanisms for asymmetric induction (Scheme 1). The development of Pd-AAA has been reviewed elsewhere; however, a specific aspect of Pd-AAA has significantly matured over the past 20 years, namely the synthesis of acyclic tetrasubstituted stereocenters. $^{2}$
Pd-AAA has been shown to be successful for inducing asymmetry on both electrophilic and nucleophilic partners. Consequently, this review is divided into these two classes of reactions, with an emphasis on vinyl epoxides as electrophiles and enolates as prochiral nucleophiles. We conclude with a discussion on cyclic pronucleophiles that are readily converted into acyclic tetrasubstituted stereocenters subsequent to the alkylation reaction, as well as some important advances made with other metals.

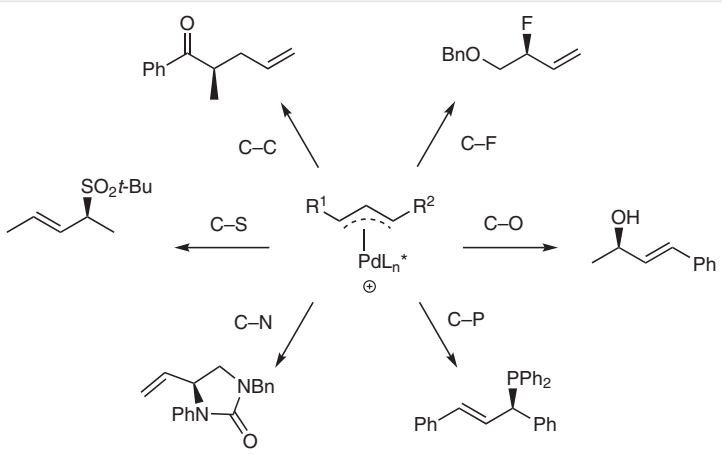

Scheme 1 Examples of stereocenters formed in Pd-AAA reactions

\section{Stereocontrol on Prochiral Electrophiles}

In the case of Pd-allylic alkylation, the most common mechanism operative involves an initial coordination of a chiral $\operatorname{Pd}(0)$ catalyst with an olefin bearing a leaving group at the allylic position (Scheme 2). Ionization occurs with inversion, where the $\eta^{2}-\pi$-allyl-Pd(II) complex is situated on the opposite face to the leaving group. Alkylation of the $\mathrm{n}^{3}$ $\pi$-allyl-Pd(II) complex occurs with inversion of the stereochemistry about $\mathrm{Pd}(\mathrm{II})$, with simultaneous regeneration of the chiral $\operatorname{Pd}(0)$ catalyst. Because both the ionization and nucleophilic addition occur with inversion, the nucleophilic 
substitution occurs with net retention of the stereochemistry of the leaving group. An outer-sphere attack of a nucleophile is the most common pathway for soft nucleophiles $\left(\mathrm{p} K_{\mathrm{a}}<25\right)$. For hard nucleophiles, the nucleophile attacks the metal directly and undergoes an inner-sphere reductive elimination with retention of stereochemistry about $\mathrm{Pd}(\mathrm{II})$, and overall net inversion of stereochemistry.

Nucleophiles such as ketone enolates alkylate at the $\alpha$ carbon, producing a stereocenter on the nucleophile. In this case, asymmetric induction can be difficult to achieve since the $\mathrm{C}-\mathrm{C}$ bond forming event most commonly occurs via an outer-sphere mechanism and the nucleophile remains distal to the chiral information about the metal-ligand environment. This mode of asymmetric induction will be discussed in Section 3.

Alkylation of allyl electrophiles bearing substituents, although typically much easier substrates for obtaining asymmetric induction, operate via more complicated mechanisms involving $\pi-\sigma-\pi$ equilibration of the $\pi$-allyl intermediate (Scheme 3d). Additionally, the enantiodeter-
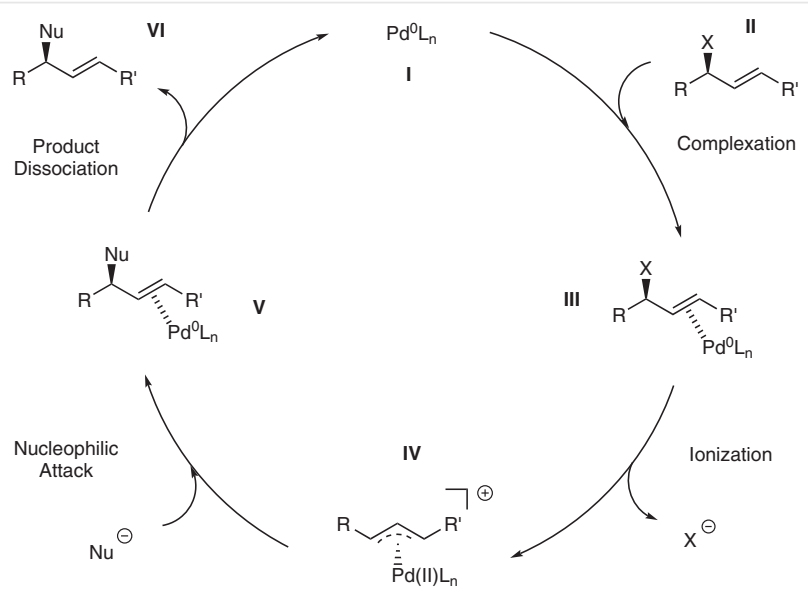

Scheme 2 Mechanism of regio- and stereospecific Pd-catalyzed AA

mining step of the reaction may occur during any step of the catalytic cycle, save for dissociation of the alkylation product. In Pd-AAA, only two mechanisms are likely to be

\section{Biographical Sketches}
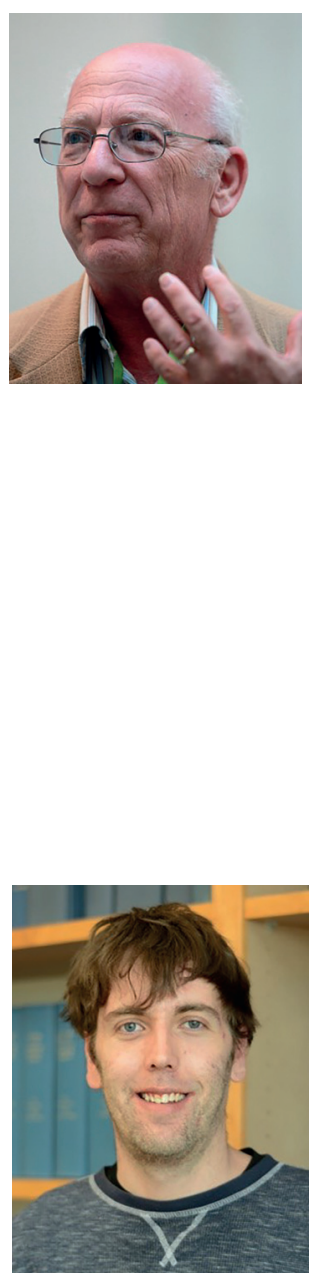

Barry M. Trost was born in Philadelphia, Pennsylvania. He obtained a BA degree from the University of Pennsylvania in 1962 and Ph.D. degree just three years later at the Massachusetts Institute of Technology (1965). He directly moved to the University of Wisconsin where he was promoted to Professor of Chemistry in 1969 and subsequently became the Vilas Research professor in 1982. He joined the faculty at Stanford as Professor of Chemistry in 1987 and became Tamaki Professor of Humanities and Sciences in 1990. In addition, he has been Visiting Professor in Germany (Universities of Marburg, Hamburg, Munich, and Heidelberg), Denmark (University of Copen-

Johnathan E. Schultz grew up in the southwestern North Dakota and west-central Minnesota. He attended North Dakota State University in Fargo, ND where he graduated Summa Cum Laude with a BS degree in Chemistry and a minor in Math- hagen), France (Universities of Paris VI and Paris-Sud), Italy (University of Pisa), and Spain (University of Barcelona). He received honorary degrees from the Université Claude-Bernard (Lyon I), France (1994), and Technion - Israel Institute of Technology, Haifa, Israel (1997). In recognition of his many contributions, Professor Trost has received a large number of awards, a few among which are the ACS Award in Pure Chemistry (1977), the Dr. Paul Janssen Prize (1990), the ASSU Graduate Teaching Award 91991), Bing Teaching Award (1993), the ACS Roger Adams Award (1995), the Presidential Green Chemistry Challenge Award (1998), the Belgian Organic Synthesis Sym-

ematics. He conducted undergraduate research in the laboratories of Gregory R. Cook with research studies on the synthesis of isoform selective histone deacetylase inhibitors as well as nucleophilic allylation methodology. He is currently posium Elsevier Award (200), The ACS Nobel Laureate Signature Award for Graduate Education in Chemistry (2002), the ACS Cope Award (2004), the Nagoya Medal (2008), the Ryoji Noyori Prize (2013), the International Precious Metals Institute's Tanaka Distinguished Achievement Award (2014), the German Chemical Society's August-Wilhelm-von-Hofmann Denkmünze (2014), the Tetrahedron Prize (2014), and the ACS Linus Pauling Award (2015). Professor Trost has been elected a fellow of the American Academy of Sciences (1982) and a member of the U.S. National Academy of Sciences (1980).

pursuing his Ph.D. studies at Stanford University as a research assistant in the laboratories of Barry M. Trost. His research has focused on Pd-catalyzed allylic alkylation strategies for the synthesis of acyclic tetrasubstituted stereocenters. 
operative in the synthesis of acyclic tetrasubstituted stereocenters on the electrophile, namely differentiation of enantiotopic olefin faces (Scheme $3 b$ ) and $\pi-\sigma-\pi$ equilibration (Scheme 3d). In most cases, the chiral ligands employed in Pd-AAA are phosphines, and a variety of scaffolds have arisen from the many creative approaches toward acyclic stereocontrol in allylic alkylation (Figure 1).

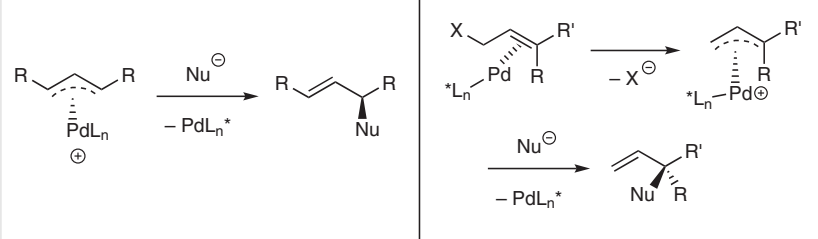

c) Differentiation of enantiotopic leaving groups

d) $\quad \pi-\sigma-\pi$ Equilibration

"x.

$\rightarrow$

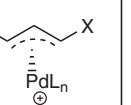

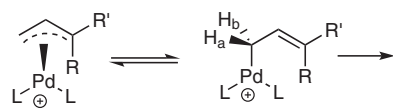

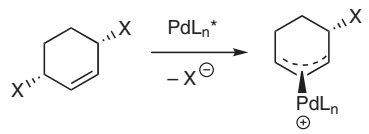

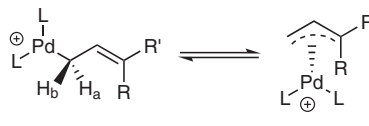

Scheme 3 Modes of asymmetric induction on electrophile

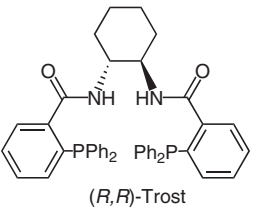

L1

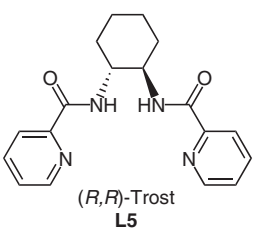

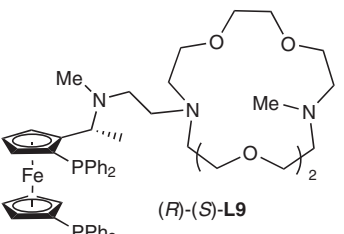

$\mathrm{PPh}_{2} \quad(R)-(S)-\mathrm{Lg}$

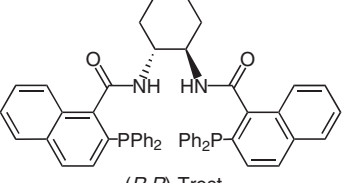

$(R, R)$-Trost

L2

$(S)-(R)-\mathbf{L} 10$

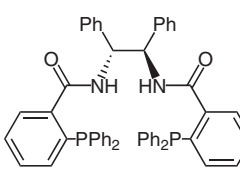

$(R, R)$-Trost L3

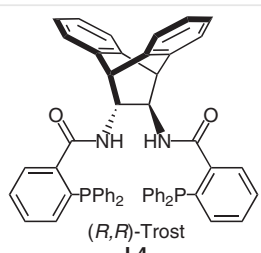

L4

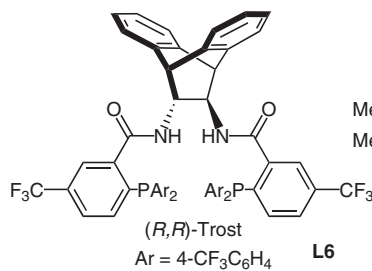

(lil]

(R)-L7

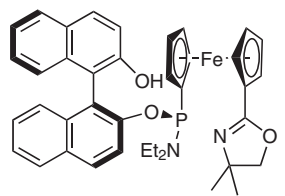

$\left(S, R_{P H O S}, R\right)$-L8
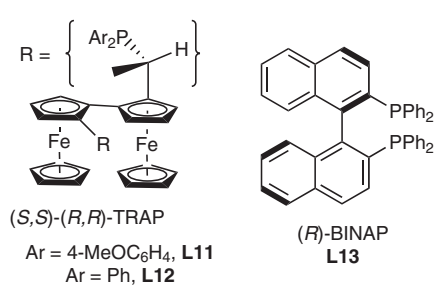

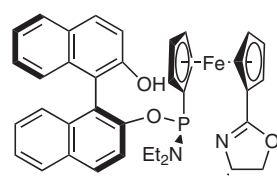

$\left(S, S_{\text {PHOS }}, R\right)-\mathrm{L} 14{ }^{i-P^{*}}$
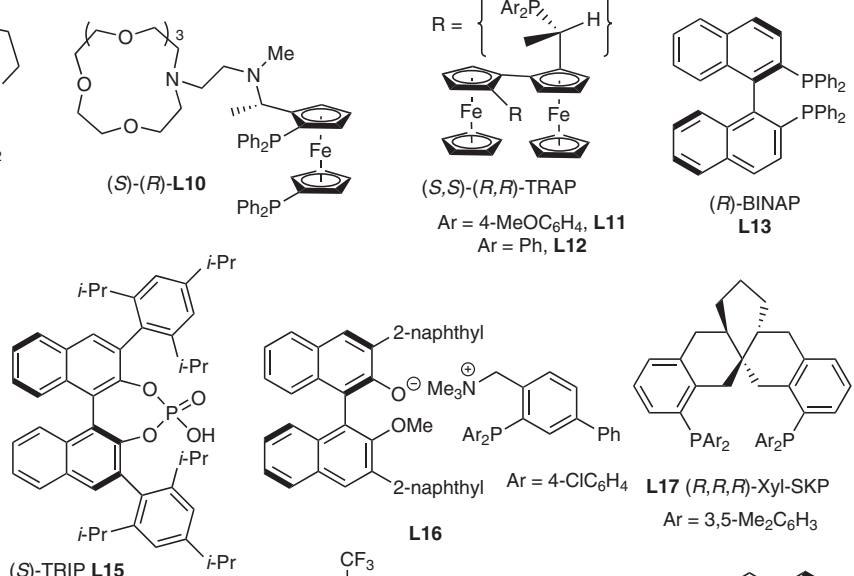

L16 (S)-TRIP L15<smiles>COc1c(F)c(F)c(S(=O)(=O)N[C@@H](C(=O)O)C(C)C)c(F)c1F</smiles><smiles>CC(C)(C)[C@H]1COC(c2ccccc2P)=N1</smiles><smiles>CC(C)(C)[C@H]1COC(c2cc(C(F)(F)F)ccc2P(c2ccc(C(F)(F)F)cc2)c2ccc(C(F)(F)F)cc2)=N1</smiles><smiles>OC[C@H]1N=C(c2ccccc2P)OC1c1ccccc1</smiles>

PHOX

Figure 1 Structures of chiral ligands used in Pd-AAA strategies toward acyclic tetrasubstituted stereocenters 


\subsection{Reactions of Isoprene Monoepoxide}

The potential of achieving Pd-AAA with isoprene monoepoxide (1) was an attractive pursuit, due to the prospect of achieving high enantioinduction for alkylation at the branched position (Scheme 4). The Trost group has achieved branch-selective alkylation for carbon, ${ }^{3}$ oxygen, ${ }^{4,5}$ and nitrogen ${ }^{6-8}$ nucleophiles, affording valuable chiral acyclic tetrasubstituted building blocks containing orthogonal hydroxymethyl and vinyl functional group handles.

$$
\underset{1}{\stackrel{\mathrm{Pd}(0) \text { cat. }}{\mathrm{L}^{*} \text { cat }}} \stackrel{\mathrm{NuH}}{\substack{\text { inear achiral } \\ \text { product }}}
$$

Scheme 4 Pd-AAA strategy for the synthesis of acyclic tetrasubstituted building blocks using electrophilic isoprene monoepoxide

These reactions constitute a dynamic kinetic asymmetric transformation (DYKAT), whereby racemic isoprene monoepoxide is ionized by a palladium catalyst, with the initially formed $\pi$-allyl species bearing an opposite sense of chirality or opposite syn/anti configuration ${ }^{9}$ (Scheme 5). Since the unbranched terminus of the $\pi$-allyl contains two hydrogen substituents, the $\eta^{1}-\sigma-\operatorname{Pd}(\mathrm{II})$ complex allows for rotation from one stereoisomer isomer to the other without syn/anti isomerization (Scheme $5 a$ ). Although $\pi-\sigma-\pi$ equil- ibration may occur at the branched carbon (Scheme 5b), this pathway is unproductive since both the $\pi$-allyl stereochemistry and the syn/anti configuration have isomerized.

An important structural consideration for this reaction also involves the equilibrium between syn and anti isomers (Scheme 6). Upon ionization of butadiene monoepoxide (2), diastereomeric $\pi$-allyl complexes are formed. The hydroxymethylene substituent is sterically more hindered than the hydrogen substituent; consequently, complex 2a is the most favored complex due to the least amount of steric clash with the ligand environment. The regioselectivity of nucleophilic addition runs counter to that typically observed for Pd-AAA, where the branched isomer is formed in high selectivity. The 'wall and flap model' shows the approximate chiral environment about each terminus of the electrophile based on chelation of a C2-symmetric ligand bearing diarylphosphines (i.e. Trost ligand, BINAP).

In the case of isoprene monoepoxide (1), the methyl and hydroxymethylene substituents are sterically very similar; however, the presence of an alkoxide from the epoxide opening renders the two electronically dissimilar (Scheme 7a). Two factors dictate alkylation at the branched terminus, namely: 1 . The alkoxide leaving group often acts as a base for the pronucleophile and engages in hydrogen bond directed alkylation of the nucleophile. 2. Ligand and additive effects can alter the most favorable trajectory of the incoming nucleophile toward the branched product. ${ }^{10}$ The a.)<smiles>C=CC(C)=C(C)CO</smiles><smiles>C/C(=C\[13CH]([13CH3])[13CH3])CO</smiles><smiles>CI</smiles><smiles>[3H][Pb](I)C(C)(C)/C=C(\C)CO</smiles><smiles>C=CC(C)=C(C)CO</smiles>

b.)

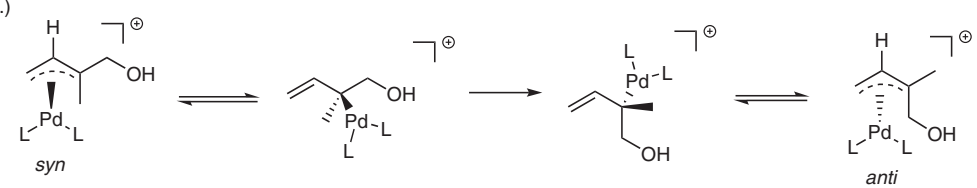

Scheme 5 Mechanism of dynamic kinetic asymmetric transformation (DYKAT) of isoprene monoepoxide

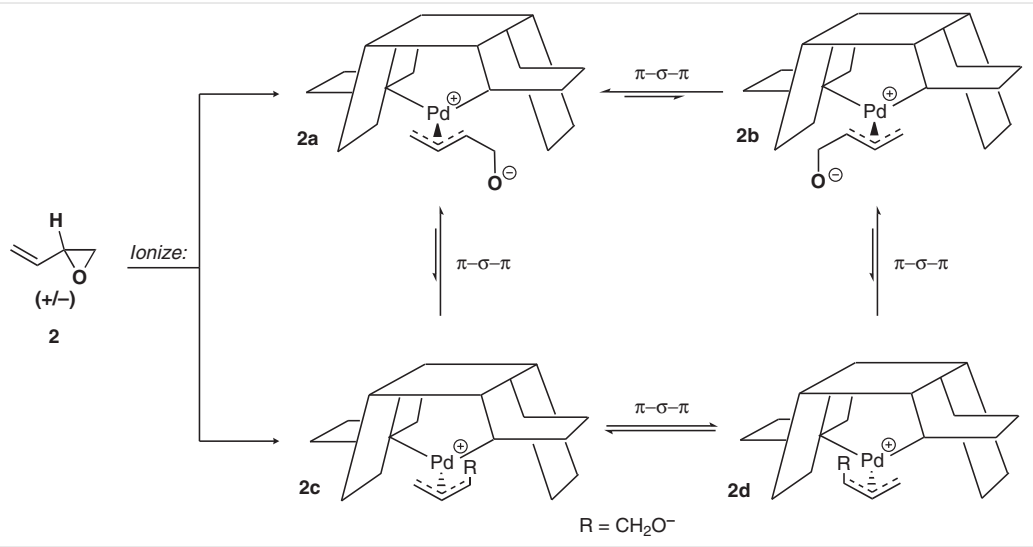

Scheme 6 Wall and flap model as a rationale for regio- and enantioselectivity in allylic alkylation with butadiene monoepoxide 
outer-sphere nucleophilic attack occurs with inversion of the stereochemistry of the $\pi$-allyl, and each enantiomer of product can be obtained from two of the stereoisomeric complexes (Scheme 7b).

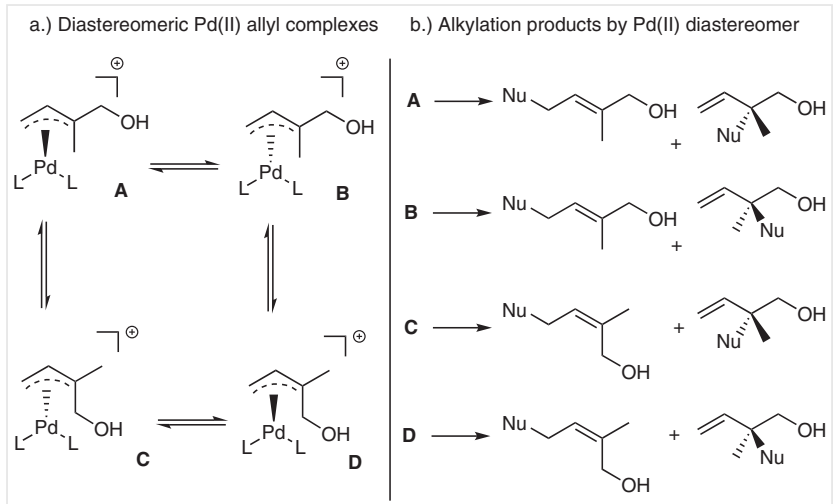

Scheme 7 Mechanistic pathways for Pd-AAA of isoprene monoepoxide

Methanol was shown to alkylate at the branched carbon with high enantioselectivity in the Pd-AAA of isoprene monoepoxide (Scheme 8). ${ }^{4}$ The use of catalytic borane was crucial for reactivity, as the reaction proceeded with little conversion in its absence. Initially, stoichiometric trimethyl borate $\left[\mathrm{B}(\mathrm{OMe})_{3}\right]$ was used in the reaction, affording the product in $80 \%$ yield and $2 \%$ ee. It was envisioned that the stoichiometric use of borane results in too rapid a reaction, such that equilibration of isoprene monoepoxide cannot occur prior to nucleophilic attack. Use of catalytic triethylborane in the presence of methanol produced diethylmethoxyborane as catalyst, and these conditions proved optimal for enantioselectivity.

Because of the lower acidity of aliphatic alcohols, their use in Pd-AAA has remained limited; however, the kinetic effect imparted by the boron additive renders this reaction favorable in alkylation of vinyl epoxides (Scheme 9a). ${ }^{4} \mathrm{Ad}-$ ditionally, the unimolecular mechanism accounts for the

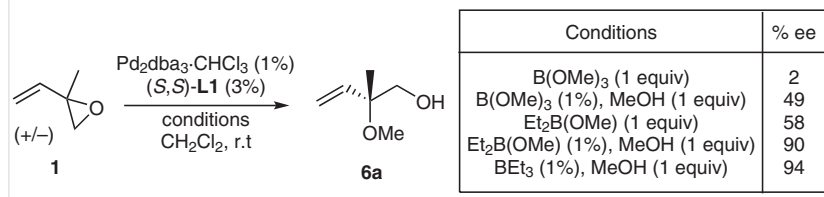

Scheme 8 Optimization of allylic etherification with isoprene monoepoxide

high selectivity for the branched product. Primary alcohols 3 undergo the alkylation chemoselectively over secondary alcohols. Additionally, the high yields indicate the product alcohol $\mathbf{6}$ is not competitive with primary alcohol substrate 3, presumably due to either a slow alkylation reaction or a small population as the alkoxydiethylborane species 4 (Scheme 9b).

The reaction scope shows several primary alcohols 3 were competent nucleophilic partners in this reaction (Scheme 10). ${ }^{4}$ For substrates with low enantioselectivity using triethylborane as catalyst, it was reasoned that etherification was occurring faster than the required $\pi$-allyl equilibration. Use of the more bulky tri-sec-butylborane proved useful for solving this problem $(\mathbf{6 b}, \mathbf{6 d}, \mathbf{6 g})$. With a hampered rate of etherification, the products were formed with higher enantioselectivity. Spontaneous cyclization to a hemiketal (6d) or lactone (6b) occurred when the nucleophilic alcohol contained a pendant ketone or methyl ester respectively. The etherification product of 4-methoxybenzyl alcohol addition $\mathbf{6 c}$ is a particularly useful synthetic precursor due to the ubiquity of PMB-protected alcohols in synthetic sequences.

A net addition of nucleophilic hydroxide was discovered for this reaction using a mixed system of triethylborane and sodium hydrogen carbonate (Scheme 11$).{ }^{5}$ Upon ionization, a borinic ester intermediate is formed that directs the alkylation of hydrogencarbonate to the branched position with high enantioselectivity. The unstable carbonate product 7 undergoes decarboxylation to directly afford the tertiary alcohol product $\mathbf{8}$.

a.) Alkoxydiethylborane-directed allylic etherification of isoprene monoepoxide

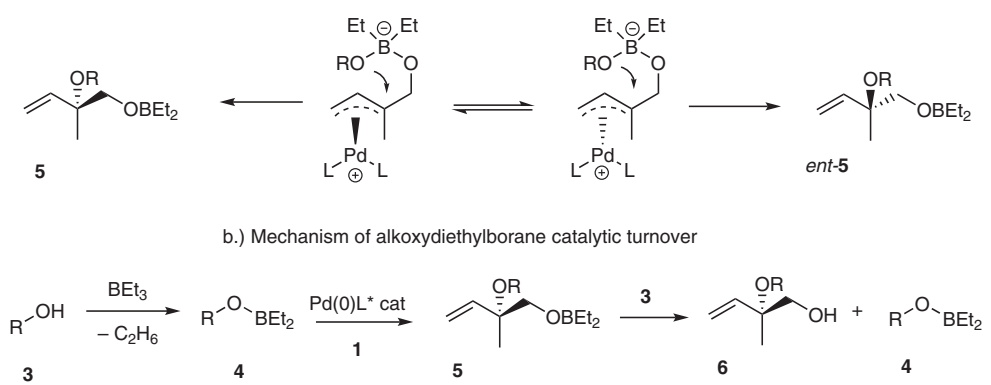

Scheme 9 Borane co-catalyst in Pd-catalyzed regio- and enantioselective allylic etherification of isoprene monoepoxide 

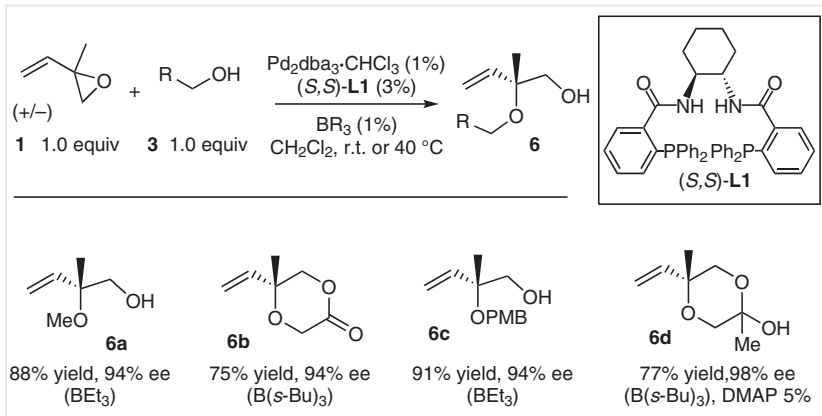

$\left(\mathrm{B}(\mathrm{s}-\mathrm{Bu})_{3}\right)$, DMAP $5 \%$
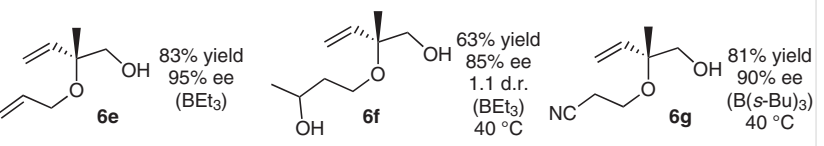

Scheme 10 Select examples of tertiary ether synthesis with isoprene monoepoxide

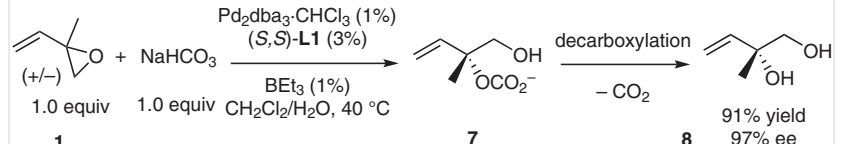

Scheme 11 Pd-AAA of isoprene monoepoxide with sodium hydrogen carbonate in the presence of borane co-catalyst

In the absence of borane additive; however, the carbonate product 9 was isolated (Scheme 12). ${ }^{5}$ The difference in reaction outcomes was attributed to the attack of carbon dioxide by the alkoxide leaving group. This system proved more challenging for optimization due to the lability of $\mathbf{9}$ to racemization. In the presence of tetrabutylammonium chloride, the product was isolated with high enantioselectivity at low conversion, but was nearly racemic upon completion of the reaction. However, sodium hydrogen carbonate in phosphate buffer resulted in high enantioselectivity at high conversion. Under the optimized conditions, low catalyst loading in the absence of buffer proved effective for achieving high enantioselectivity.

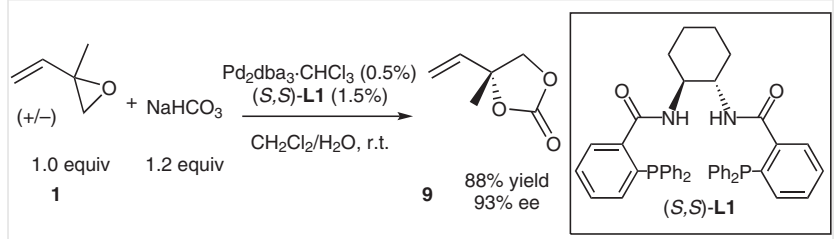

Scheme 12 Pd-AAA of isoprene monoepoxide with sodium hydrogen carbonate in the absence of borane co-catalyst.

Carbon nucleophiles were successfully applied in this chemistry using nitromethane (10) or $\beta$-keto esters (Scheme 13). ${ }^{3}$ These reactions were pioneering for the metal-catalyzed synthesis of acyclic all-carbon quaternary stereocenters, which has been an active area of pursuit since the development of this chemistry. ${ }^{11}$ The product from ni- tromethane addition $\mathbf{1 1}$ is particularly valuable, as the resulting nitromethylene substituent serves as an acyl anion equivalent, orthogonal to the two other functional group handles (Scheme 13a). In the case of $\beta$-keto ester 12, the hydroxymethyl group spontaneously cyclizes to form a hemiketal 13 upon allylic alkylation (Scheme 13b). A retroaldol reaction of $\mathbf{1 3}$ proceeds cleanly in the presence of tetrabutylammonium fluoride (TBAF) to furnish acyclic 14.

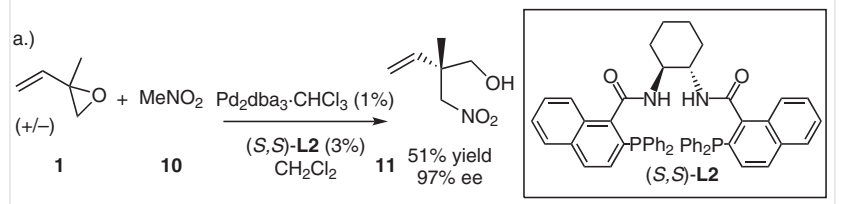

b.)

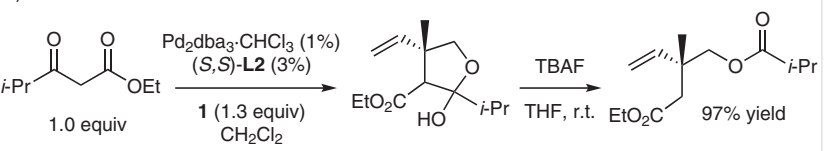

$1374 \%$ yield, $97 \%$ ee

14

Scheme 13 Pd-AAA of isoprene monoepoxide with carbon nucleophiles

Isoprene monoepoxide has been successfully alkylated by phthalimide (15) to afford the branched, $\alpha$-tertiary imide 16 (Scheme 14). ${ }^{7}$ The regioselectivity is invoked to be the result of both hydrogen bonding and ligand-directed effects. Achiral dppe afforded exclusively the linear product. The reaction with chiral ligand $\mathbf{L} 2$ proved to be solvent, base, and temperature sensitive. High enantioselectivity could be achieved without exogenous base; however, this resulted in exceedingly long reaction times. Prolonged reaction time after completion of the reaction resulted in a higher proportion of branched product, likely due to re-ionization of $\mathbf{1 6 .}$
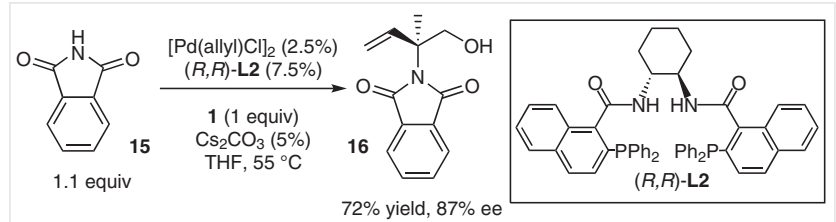

Scheme 14 Pd-AAA of isoprene monoepoxide with phthalimide

Enantiopure amino esters $\mathbf{1 7}$ were reacted with isoprene monoepoxide in a catalyst-controlled regio- and diastereoselective allylic alkylation (Scheme 15). ${ }^{8}$ A subsequent cyclization by KCN afforded 2-oxomorpholines 18 with high diastereoselectivity. Although the products of the sequence are cyclic, the product of the first step of the reaction sequence is an acyclic $\alpha$-tertiary amine, demonstrating that amines react in analogy to phthalimide with isoprene monoepoxide. It was shown that catalyst control could dictate diastereodivergent pathways when using the natural amino acids. Multiple ligands were employed, due to the 
presence of match-mismatch effects unique to each amino ester. Since the enantiomeric amino acids are commercially available, all four stereoisomeric products are accessible by this route. This is a valuable feature, especially in diversityoriented approaches to compound libraries. ${ }^{12}$

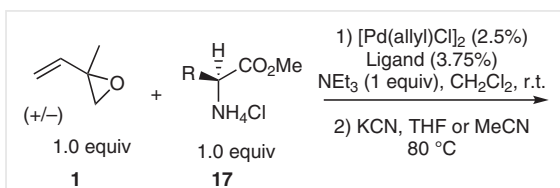

17

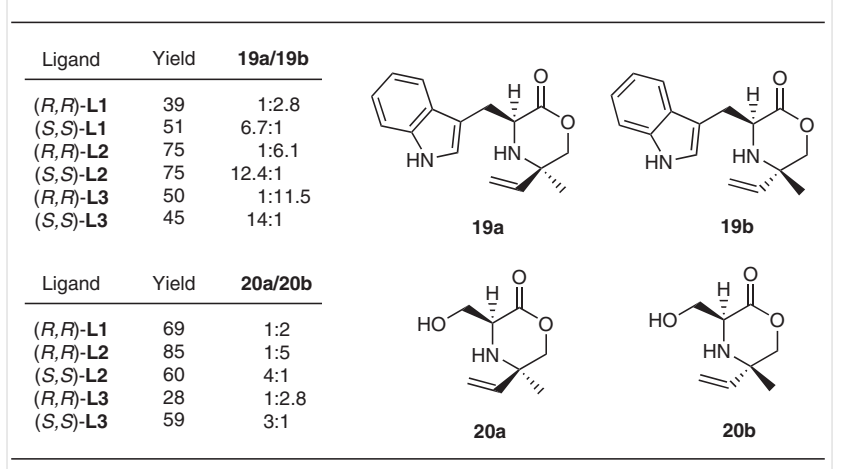
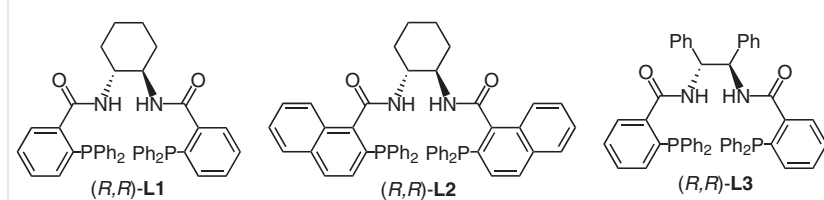

Scheme 15 Pd-AAA of isoprene monoepoxide with enantiopure amino esters

\subsection{Applications in Complex Molecule Synthesis}

Isoprene monoepoxide was successfully used in the key steps in the synthesis of hyperolactone C (26) and (+)-biyouyanagin A (29) (Scheme 16). ${ }^{13}$ The nucleophilic precursor 24 was accessed by dianion functionalization of methyl acetoacetate (21) with benzaldehyde. The necessary diazo pre- cursor 23 was synthesized in two steps from 22, and the Pd-AAA pronucleophile $\mathbf{2 4}$ was accessed by rhodium carbene insertion into an enol $\mathrm{O}-\mathrm{H}$ bond. The two vicinal tetrasubstituted stereocenters of $\mathbf{2 5}$ were formed by a regio-, enantio-, and diastereoselective Pd-AAA between 24 and isoprene monoepoxide $(\mathbf{1})$. The short reaction time proved crucial to the success of this reaction, as a host of side reactions occurred upon completion of the reaction. The $59 \%$ isolated yield of $\mathbf{2 5}$ is reflective of a modest 2.1:1 branched/linear ratio; however, the product was isolated as a single enantiomer in 26:1 d.r.

Lactonization of $\mathbf{2 5}$ catalyzed by 4 -toluenesulfonic acid produced hyperolactone $C(\mathbf{2 6})$ in a single step. For the synthesis of (+)-biyouyanagin A (29), ent-hyperolactone $C$ was readily accessed by simply changing the enantiomer of Trost L2. The efficiency of the sequence is outstanding, with the synthesis of hyperolactone $C$ requiring a longest linear sequence of six steps, and (+)-biyouyanagin A synthesized by an additional photocycloaddition with zingiberene (27) in the presence of 2 '-acetonaphthone (28).

In the total synthesis of (-)-terpestacin ${ }^{14}$ (Scheme 17), the key Pd-AAA reaction between a diosphenol $\mathbf{3 0}$ and racemic isoprene monoepoxide (1) was observed to proceed rapidly and in high yield, but with low enantioselectivity ( $\sim 50 \%$ ee). It was reasoned that the low enantioselectivity potentially resulted from a short lifetime of the $\pi$-allyl intermediate due to rapid nucleophilic attack. Addition of halide additives has been shown to increase enantioselectivity by increasing the rate of $\pi-\sigma-\pi$ equilibration. ${ }^{15}$ Increasing the concentration of tetrabutylammonium chloride displayed this effect; however, slow addition of $\mathbf{3 0}$ proved most effectual for increasing the lifetime of the $\pi$-allyl intermediate. Under optimized conditions, silylation of the product alcohol was performed in a single operation, affording product 31 in 93-95\% yield and 88-96\% ee. The chiral information of the newly formed stereocenter could be translated via a [3,3]-sigmatropic rearrangement, and di-
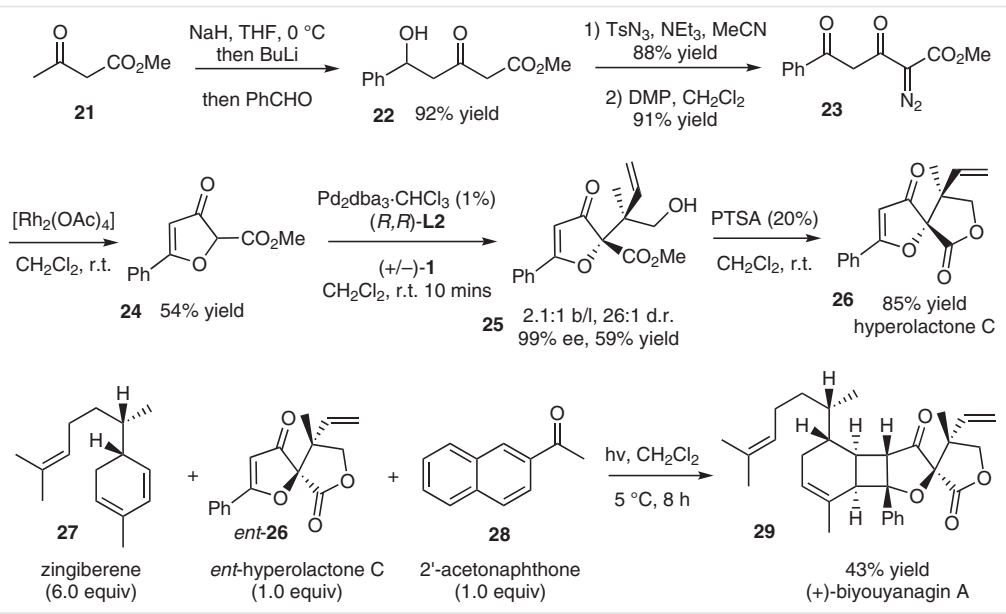

Scheme 16 Pd-AAA of isoprene monoepoxide in the total synthesis of hyperolactone $C$ and (+)-biyouyanagin A 
rect oxidation of the Claisen rearrangement product afforded the desired diketone $\mathbf{3 3}$ in 78\% yield over the sequence, with 4:1 selectivity in the formation of the resultant olefin. A Sakurai allylation of $\mathbf{3 3}$ installed an allyl functional group handle to form 34. This precursor was used in the construction of macrocycle 35. An additional catalyst-controlled PdAAA/sigmatropic rearrangement in the late stages of the synthesis afforded $\mathbf{3 8}$, which was efficiently elaborated to the target.
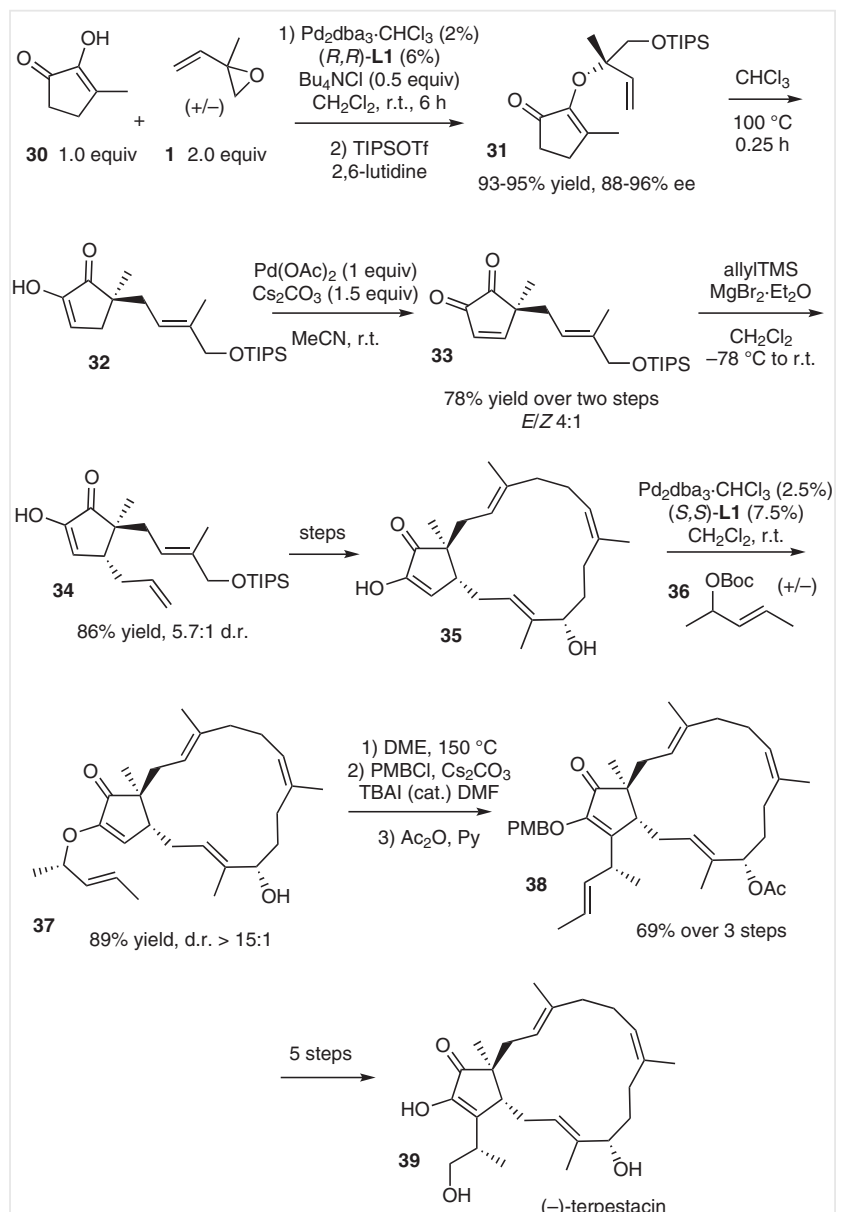

Scheme 17 Pd-AAA of isoprene monoepoxide in the total synthesis of (-)-terpestacin

The synthesis of tipranavir was accomplished by setting the stereochemistry of a tetrasubstituted and tertiary stereocenters by Pd-AAA (Scheme 18) and Mo-AAA, respectively (Scheme 19). ${ }^{16}$ A propyl-substituted vinyl epoxide 41 was accessed in two steps from 1-chloropentan-2-one (40). After addition of vinylmagnesium bromide, the tertiary alcohol product was efficiently cyclized to form 41 in $86 \%$ yield over two steps. A borane co-catalyzed Pd-AAA of the vinyl epoxide with 4-methoxybenzyl alcohol proved highly enantioselective in the construction of acyclic tertiary ether 42. Synthesis of the phenethyl side chain was readily ac- complished by Heck arylation and hydrogenation of the vinyl functional group handle. The hydroxymethylene functional group handle was homologated via an oxidation/Wittig olefination/hydroboration/oxidation sequence.

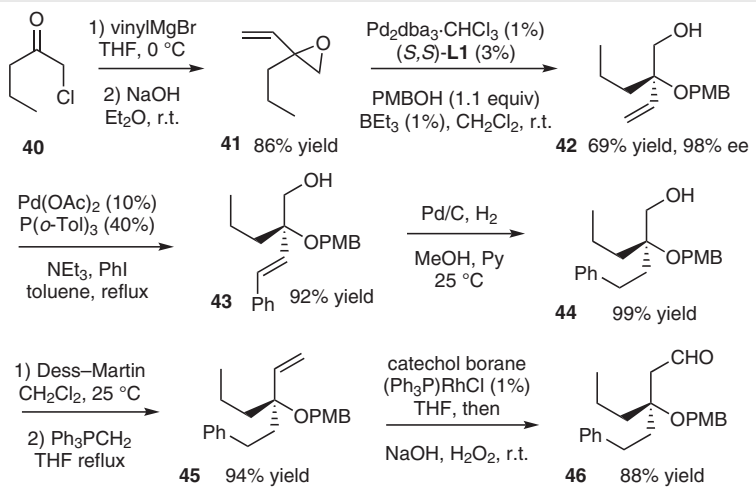

Scheme 18 Synthesis of acyclic tertiary ether fragment in the total synthesis of tipranavir

The tertiary stereocenter was synthesized by a branchselective cinnamylation of dimethyl malonate sodium salt 48 and 3-nitrocinnamyl electrophile 47 under chiral molybdenum catalysis (Scheme 19). Decarboxylation of a methyl ester afforded nucleophilic precursor 48, which was coupled with the previously prepared aldehyde $\mathbf{4 6}$ via an ester enolate aldol reaction. Oxidation of the resulting alcohol, followed by PMB deprotection provided substrate $\mathbf{5 0}$ for a sodium hydroxide mediated lactonization. Hydrogenation conditions afforded both nitro and olefin reduction, and the product 52 was completed by sulfonamide formation. A similar strategy was employed in the total synthesis of (-)malyngolide. ${ }^{17}$ Additionally, synthetic studies on amphidinolide B1, ${ }^{18}$ as well as (+)-pleuromutilin ${ }^{19}$ have employed isoprene monoepoxide in Pd-AAA for the synthesis of early chiral building blocks.

\subsection{Other Acyclic Electrophiles}

In the work of the Trost group on the prenylation of oxindoles, conditions were developed to selectively afford both the branched and linear prenylation products (Scheme 20). ${ }^{20}$ This strategy culminated in a unified approach toward flustramine natural products. For the reverse prenylated product 56, vicinal quaternary carbons are formed while setting the cyclic stereocenter in high enantioselectivity. Formation of the linear product $\mathbf{5 5}$ using the Trost $\mathbf{L 1}$ was typical of most Pd-AAA; however, the unique structural features of Trost $\mathbf{L} 2$ provide the branched product. Additionally, tetrabutylammonium difluorotriphenylsilicate (TBAT) as a halide additive improved the reaction outcome, due most likely to a required rate increase in $\pi-\sigma-\pi$ equilibration. 

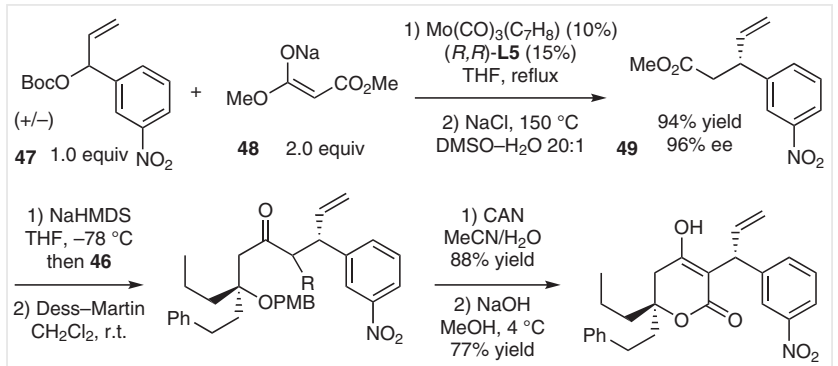

$5089 \%$ yield, $\mathrm{R}=\mathrm{CO}_{2} \mathrm{Me}$

51

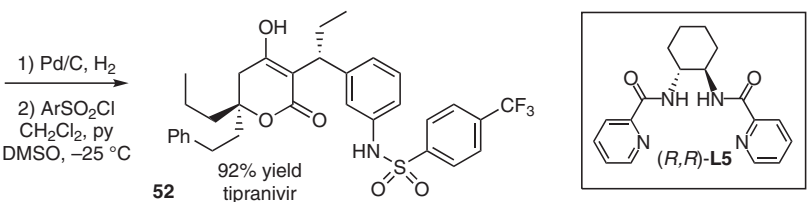

Scheme 19 A Pd- and Mo-AAA strategy for the synthesis of tipranavir

An extension of this chemistry allowed for the synthesis of an acyclic quaternary carbon stereocenter when using geranyl-type electrophiles (Scheme 21). When using racemic, branched electrophile 57, the linear and branched products were formed in equal amounts, with the branched product 58 formed with high enantio- and diastereoselectivity.

It was determined from subsequent experiments that when using achiral (Z)-60, a regio-, enantio-, and diastereoselective synthesis of vicinal quaternary stereocenters was achieved (Scheme 22). These results indicate that ionization of the electrophile is enantiodetermining with respect to the acyclic electrophile, and diastereoselective alkylation by the oxindole occurs faster than $\pi-\sigma-\pi$ equilibration. This process underscores both the versatility in controlling stereochemical reaction outcomes and the importance of understanding the underlying processes in Pd-AAA reaction optimization.

A Pd-catalyzed enantioselective allyl-allyl cross-coupling protocol was reported by Morken and co-workers for the asymmetric synthesis of acyclic quaternary stereocenters (Scheme 23). ${ }^{21}$ This process represents one of few Pdcatalyzed AAA reactions to occur with hard nucleophiles with high enantioselectivity. It was shown that both $(E)$ and $(Z)$ linear electrophiles, as well as branched racemic electrophile 62 afforded the same enantiomer of the respective product in similar yields. This result likely indicates that
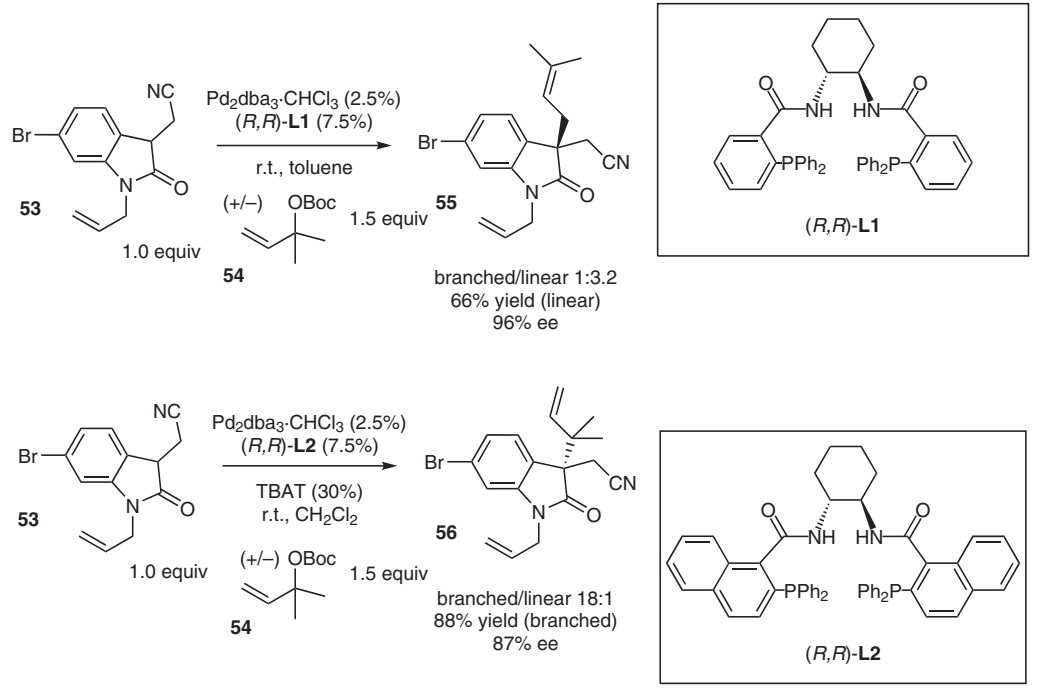

Scheme 20 Regioselective Pd-catalyzed prenylation of oxindoles

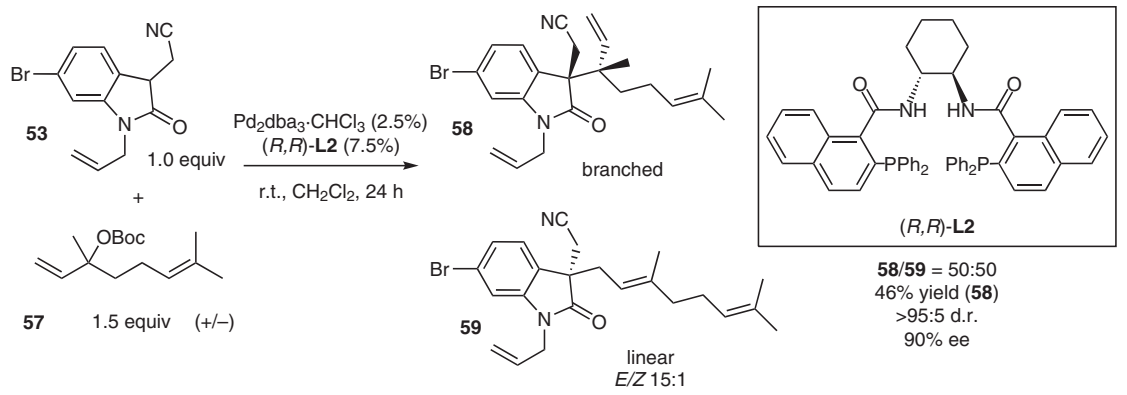

Scheme 21 A regiodivergent Pd-AAA of oxindoles using racemic branched electrophile 

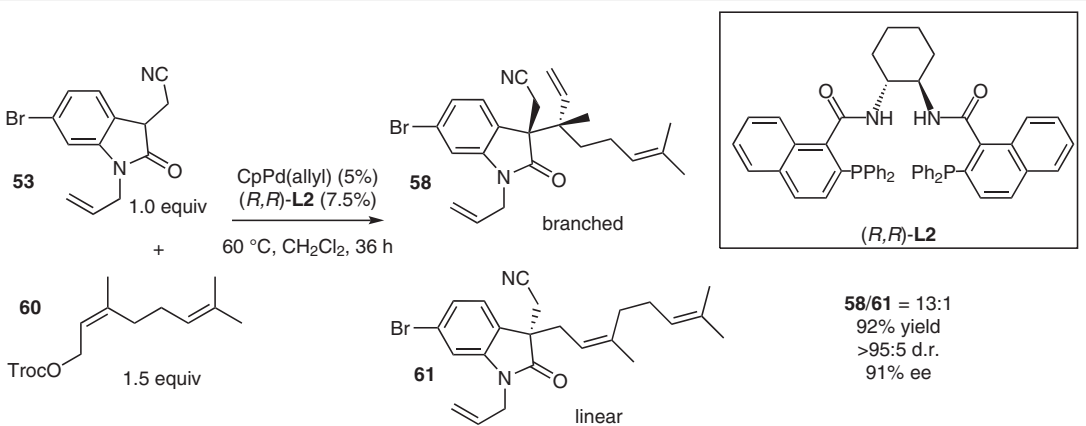

Scheme 22 Pd-catalyzed regio-, diastereo-, and enantioselective synthesis of vicinal quaternary stereocenters

rapid equilibration of the $\pi$-allyl intermediate occurs before reductive elimination, and it is ligand control of the $\pi$-allyl stereochemistry that dictates the enantioselectivity. In the reaction optimization it was observed that $\beta$-hydride elimination was a significant side product. Addition of fluoride in a THF/water mixture was shown to minimize this side reaction by acceleration of allyl transmetalation.
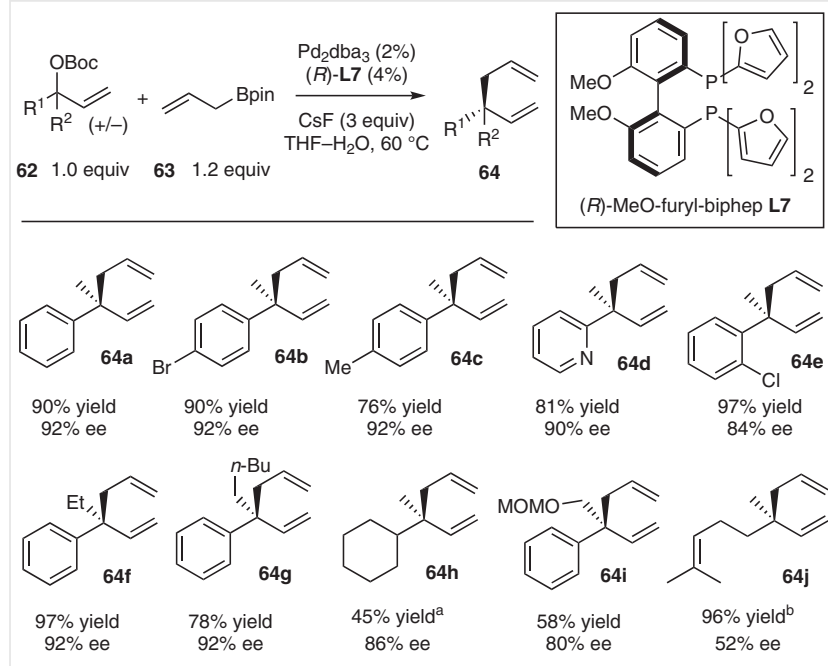

a) Tertiary allylic chloride electrophile was used. b) Linear geranyl electrophile was used.

Scheme 23 Catalytic enantioselective branch selective allyl-allyl cross coupling
The substrate scope revealed high enantioselectivities for the synthesis of acyclic benzylic quaternary stereocenters. High enantioselectivity was observed when placing branched aliphatic substituents in addition to the methyl group (64f, 64g, 64i). A modest, but appreciable enantioinduction was observed for a geranyl-type substrate $(\mathbf{6 4 j} \mathbf{j})$.

The $\mathrm{C}-\mathrm{C}$ bond-forming event is invoked to occur via a 7 membered 3,3' inner-sphere reductive elimination of bis $\left(\eta^{1}\right.$-allyl)Pd(II) complex 67 (Scheme 24). In this scenario, palladium is bound to the unsubstituted terminus of the trisubstituted allyl partner. The alternative mechanism would involve a more classical 3-membered reductive elimination; however, calculations place this pathway at $\sim 15$ $\mathrm{kcal} / \mathrm{mol}$ higher in energy. ${ }^{22}$ The source of enantioinduction in this reaction is not immediately clear. The stereocenter is created in the reductive elimination step to form 68; however, the pre-equilibrium of the $(E)$ - and $(Z)$-isomers of $\mathbf{6 6}$ may be enantiodetermining if the Re or Si pathway is significantly favored for both isomers.

The branch-selective Pd-AAA reaction has been achieved using ligands developed by the Hou group. ${ }^{23}$ Racemic tertiary allylic acetates were alkylated with modest enantioselectivity and branch/linear selectivity using dimethyl malonate as the pronucleophile (Scheme 25). Extensive optimization of ligand, solvent, additive, and base was required in the process. This ligand class offers modulation of the BINOL, phosphorus, and oxazoline chirality for achieving branch-selective Pd-AAA. The presence of high $(E)$-selectivity in the linear product $\mathbf{7 1}$ indicates that high syn/an-

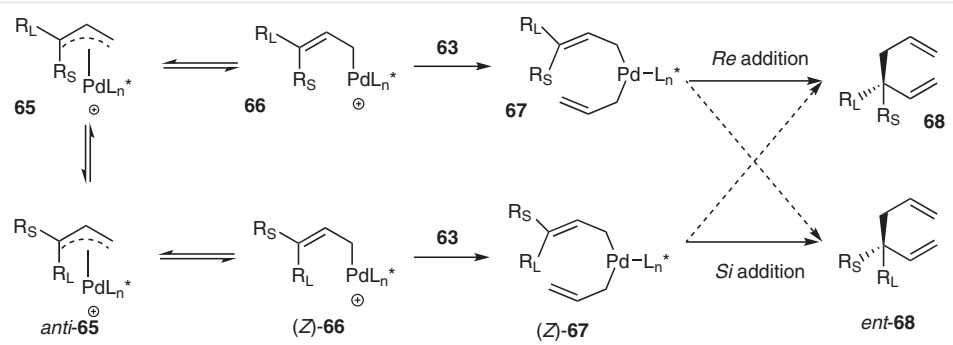

Scheme 24 Mechanism of enantioselective allyl-allyl cross coupling 
ti control is achieved in the $\pi$-allyl formation. Enantioinduction is achieved by facial discrimination of the sterically differentiated methyl and aryl substituents.

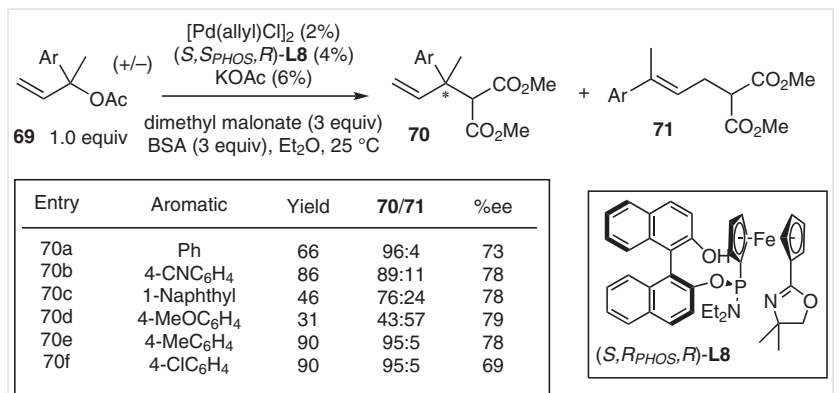

Scheme 25 Pd-catalyzed branch-selective cinnamylation of dimethyl malonate for the synthesis of acyclic quaternary stereocenters

\section{Stereocontrol on Prochiral Nucleophiles}

In Pd-AAA, achieving high enantiocontrol on nucleophiles remains inherently more difficult than achieving enantiocontrol on the electrophilic partner, due to the outersphere mechanism for nucleophilic addition. In the alkylation event, the chiral information about the metal-ligand sphere must be successfully relayed distal to the metal in order to observe catalyst differentiation of enantiotopic faces of the nucleophile. This problem is compounded by the presence of enantioconvergent and enantiodivergent allylation pathways (Scheme 26). In the case of enantioconvergent allylation (Scheme 26a), the chiral catalyst recognizes the substituents at the site of reaction. Although the restriction of controlling the enolate geometry has been removed, $\mathrm{R}^{1}$ and $\mathrm{R}^{2}$ are limited to sterically differentiable substituents (i.e. alkyl vs. aryl).

When an enantiodivergent pathway is operative (Scheme 26b), the catalyst recognizes the substituents vicinal to the site of reaction. This pathway is desirable if $R^{1}$ and

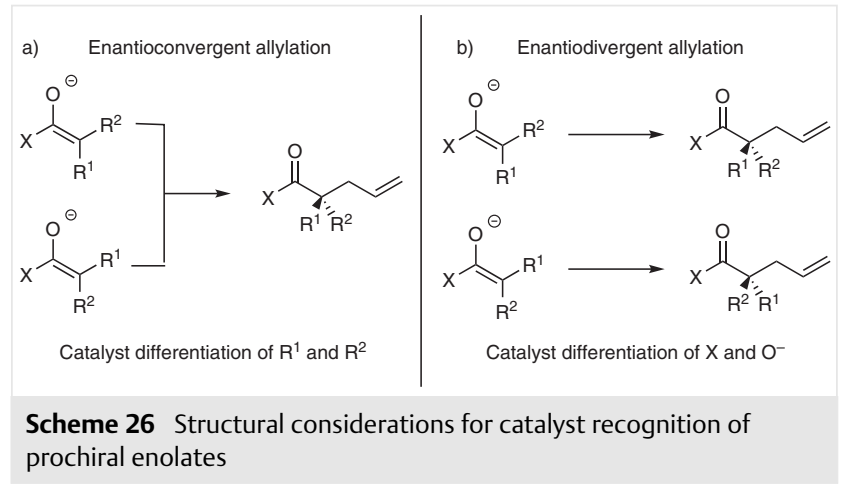

$\mathrm{R}^{2}$ are of limited steric differentiation; however, the enolate geometry must be strictly controlled in order to observe high enantioselectivity. The enantiodivergent pathway has an important advantage over the enantioconvergent pathway, since the identity of $X$ can be exploited as an achiral auxiliary and a tunable parameter for reaction optimization.

As will be seen, both the $\alpha$ substituents and the enolate geometry are commonly recognized by the catalyst in the allylation event. In this case, the presence of match-mismatch effects will be apparent when both enolate isomers can be synthesized in geometrically pure form. The stereofidelity of the enolate is assumed to remain intact during enantiodivergent allylations; however, oxygen-to-carbon migration may provide a mechanism for erosion of the enolate geometry if palladium enolates are formed as intermediates (Scheme 27a). Isomerization of palladium enolates has been exploited for the Pd-AAA DYKAT of butenolide electrophiles with phenolic nucleophiles (Scheme 27b). ${ }^{24}$ In this scenario, the palladium enolate is formed on the butenolide electrophile (Scheme 27c), and the mechanism for isomerization of the $\pi$-allyl species involves carbon-tooxygen migration.

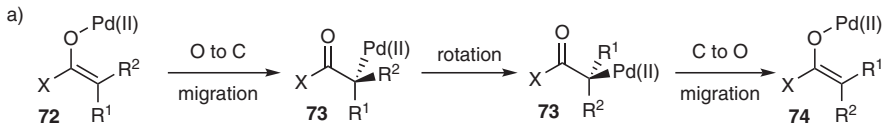

b)

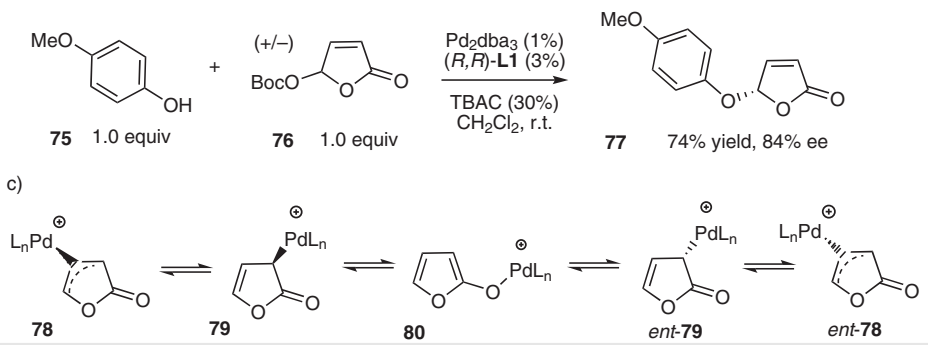

Scheme 27 Potential mechanism for the erosion of enolate stereochemistry 


\subsection{Intermolecular Alkylation of Prochiral Nucleo- philes}

Many of the first syntheses of acyclic tetrasubstituted stereocenters by reactions of prochiral nucleophiles were discovered by the Ito group. In 1992, allylation of an acyclic 1,3-diketone 81 (Scheme 28a) was reported in modest enantioselectivity by employing a point and planar chiral ferrocenyl ligand scaffold bearing an aza-crown ether. ${ }^{25}$ In 1996, allylation of $\alpha$-nitro ester $\mathbf{8 3}$ was achieved by a similar strategy (Scheme 28b). ${ }^{26}$ In order to enhance enantioselectivity upon nucleophilic attack of a $\pi$-allyl palladium(II) complex, it was envisioned that linking a crown ether to chiral phosphine ligands would allow for recognition of the nucleophile counterion. In this case, the chiral information of the catalyst could be relayed distal the site of the reaction, thus solving the problem of poor selectivity when using prochiral nucleophiles in Pd-AAA. In both cases, significant optimization of the crown ether and counterion was required to obtain the enantioselectivity.

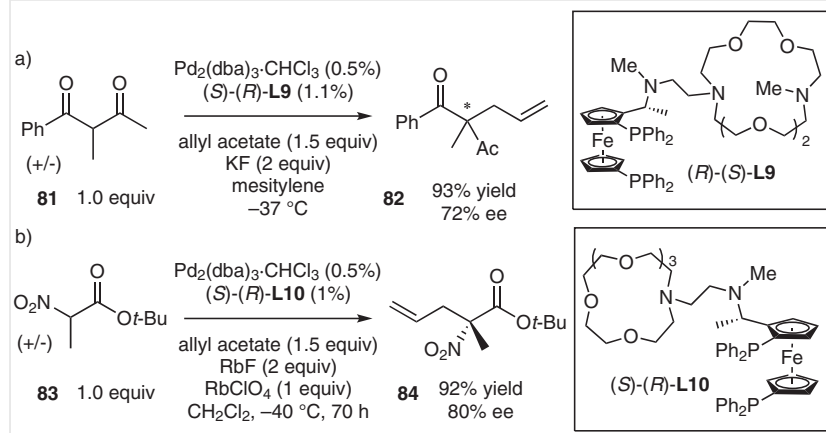

Scheme 28 Asymmetric allylation of a 1,3-diketone and an $\alpha$-nitro ester by counterion recognition of a chiral phosphine ligand

A dual catalytic approach to Pd-AAA was achieved by exploiting chiral rhodium enolate chemistry (Scheme 29). ${ }^{27}$ It had been shown that rhodium salts form a trans bis- phosphino complex that is bound to the nitrogen of cyanoderived enolates. ${ }^{28}$ This chemistry had been previously applied to Michael additions and aldol reactions. ${ }^{29}$ Using ferrocenyl ligands developed in the Ito group, they were able to achieve high enantioselectivity in the allylation of cyano ester 85, cyanoamide 88, and $\alpha$-cyanophosphonate $\mathbf{9 0}$ under $\pi$-allyl-Pd catalysis. Potentially, the ligand forms complexes with both rhodium and palladium, and the chirality of each species is synergistic in the alkylation event.

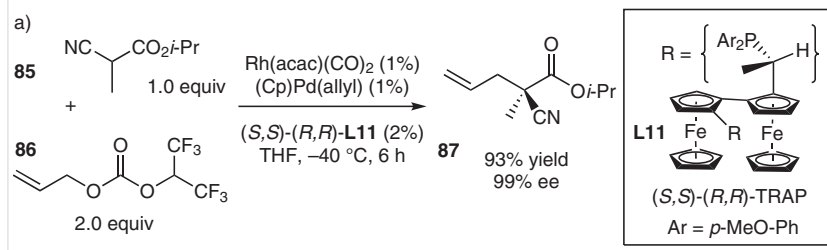

$$
\text { b) }
$$

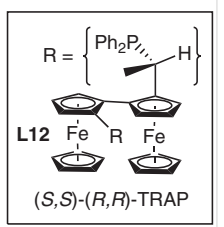

Scheme 29 Dual catalytic Pd-AAA of chiral cyano-rhodium enolates

An early report on asymmetric induction utilizing acyclic nucleophiles was provided by the Ito group ${ }^{30}$ in their $\operatorname{Pd}(0) / B I N A P-c a t a l y z e d ~ P d-A A A$ of $\alpha$-acetamido- $\beta$-keto esters 92 (Scheme 30). High levels of enantioselectivity were reported when using potassium tert-butoxide as base. Additionally, high geometric control of the resulting olefinic products 94 was reported, even for commonly difficult aliphatic allylic acetates $(\mathbf{9 4 g}, \mathbf{9 4 h}, \mathbf{9 4 i})$. The highest enantioselectivities were observed for cinnamylation reactions (94c, 94d, 94e, 94f), although simple allylations proceeded in good enantioselectivity.
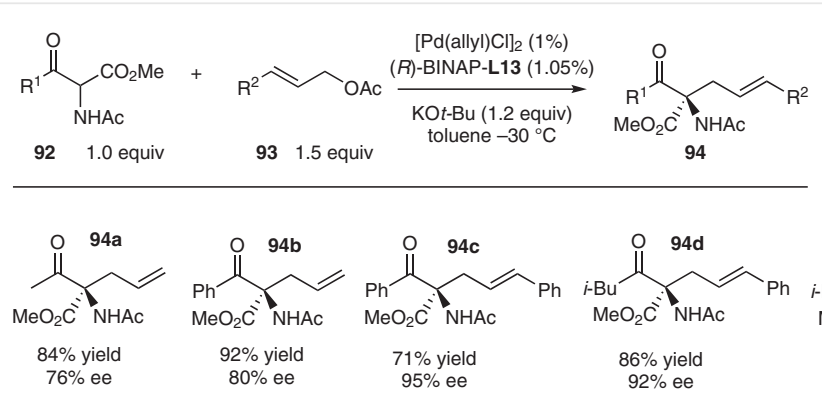

$$
\begin{gathered}
\mathrm{M} \% \text { yield } \\
92 \% \text { ee }
\end{gathered}
$$

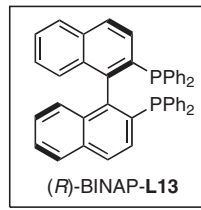

$$
\begin{gathered}
85 \% \text { yield } \\
91 \% \text { ee }
\end{gathered}
$$

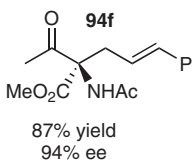

$$
\begin{gathered}
96 \% \text { yield } \\
87 \% \text { ee }
\end{gathered}
$$
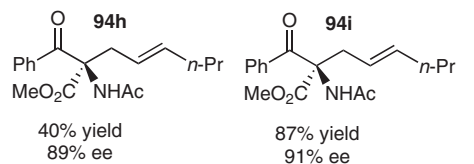

Scheme 30 Pd/BINAP-catalyzed allylation of $\alpha$-acetamido- $\beta$-keto esters 
Curiously, the reaction outcome was largely independent of whether the branched 96 or linear $(Z)$-95 electrophilic substrate was used (Scheme 31). It was proposed that any stereo- or regiochemistry present in the starting electrophiles is lost due to a rapid $\pi-\sigma-\pi$ equilibration relative to intermolecular nucleophilic alkylation.

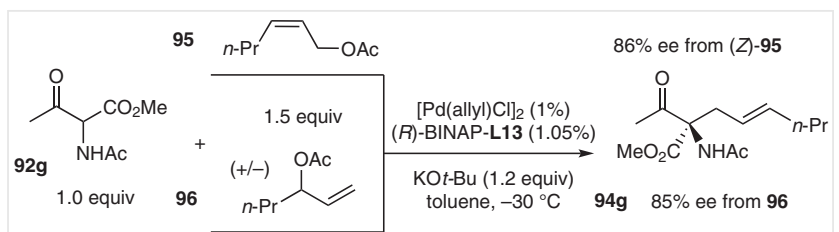

Scheme 31 Independence of electrophile regio- and stereochemistry on reaction outcome

A similar catalytic system was shown to provide allylation products for $\alpha$-acetamido- $\beta$-ketophosphonate nucleophiles 97 (Scheme 32). ${ }^{31}$ A possible explanation for the high enantioselectivity in this acyclic system is control of the enolate geometry by chelation between the phosphonate and enolate oxygen atoms. The highest enantioselectivity was observed for 3-substituted allylic electrophiles 93; allylation proceeded with only modest enantioselectivity.

Other work by the Ito group demonstrated acyclic control in the cinnamylation of 1,3-diketones (Scheme 33). ${ }^{32}$ Two examples demonstrated cinnamylation of acyclic 1,3diketones in good enantioselectivity. Similar levels of asymmetric induction on cyclic substrates were also reported. Cryogenic temperatures were required for high enantiocontrol in this reaction, however, in conjunction with their work on $\alpha$-acetamido- $\beta$-keto esters and $\alpha$-acetamido- $\beta$-ketophosphonates, these reactions serve as some of the earliest examples of Pd-AAA with stereocontrol on acyclic nucleophiles under simple catalyst conditions.

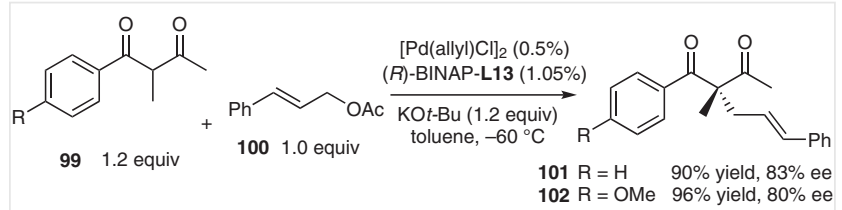

Scheme 33 Examples of acyclic 1,3-diketone cinnamylation

Hou and co-workers have demonstrated Pd-AAA of acyclic diphenylamides ${ }^{33}$ using the ferrocenyl-based ligands that they developed (Scheme 34). In most cases, $\alpha$-tertiary carbon centers were synthesized, however, the report contains two examples of the asymmetric synthesis of acyclic tetrasubstituted stereocenters. The $\mathrm{N}, \mathrm{N}$-diphenylamide was found to be optimal in the initial optimization. Subsequent variation of the chirality on the oxazoline, phosphorus, and the BINOL moieties of the ligand proved crucial for achieving high enantioselectivity.

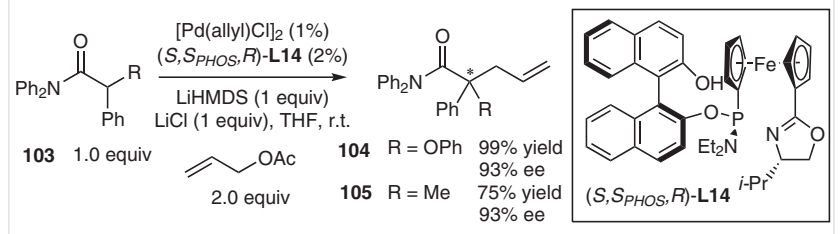

Scheme 34 Synthesis of acyclic tetrasubstituted stereocenters by $\alpha$-alkylation of $\mathrm{N}, \mathrm{N}$-diphenylamides

List and Jiang were able to demonstrate the asymmetric $\alpha$-allylation of $\alpha$-arylpropanals $\mathbf{1 0 7}$ under triple chiral acid/enamine/palladium catalysis (Scheme 35$).{ }^{34}$ An achiral palladium source was used in the reaction, and asymmetric induction was achieved by achiral amine catalyst (e.g., 106) in the presence of $(S)$-TRIP phosphoric acid L15. Optimization of the amine catalyst showed benzhydrylamine (106) to be differential among other achiral benzylic amines. In addition to allyl alcohol, more substituted alcohols $\mathbf{1 0 8}$ were effective in the reaction. Although the reaction showed impressive display of control for asymmetric quaternary carbon synthesis, the method was limited to $\alpha$-arylpropanals, as an elongation of the aliphatic aldehyde side chain resulted in diminished enantioselectivity (109f).

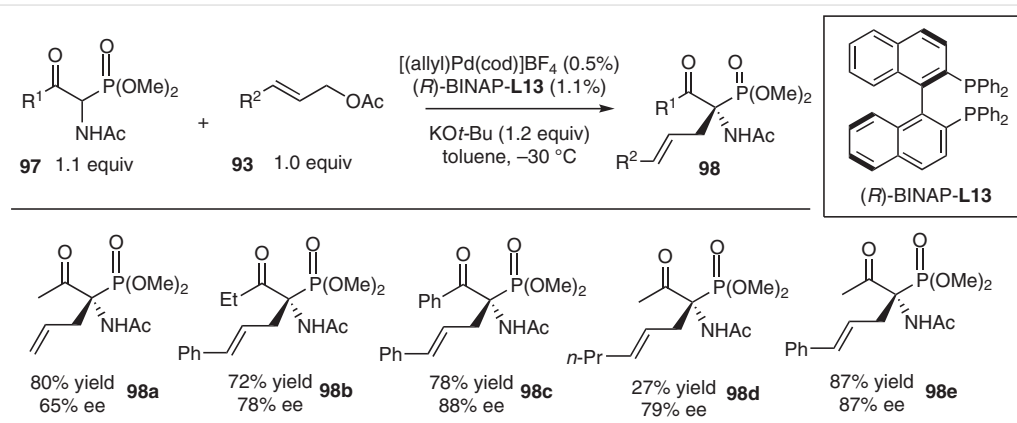

Scheme 32 Pd-AAA of $\alpha$-acetamido- $\beta$-ketophosphonates 

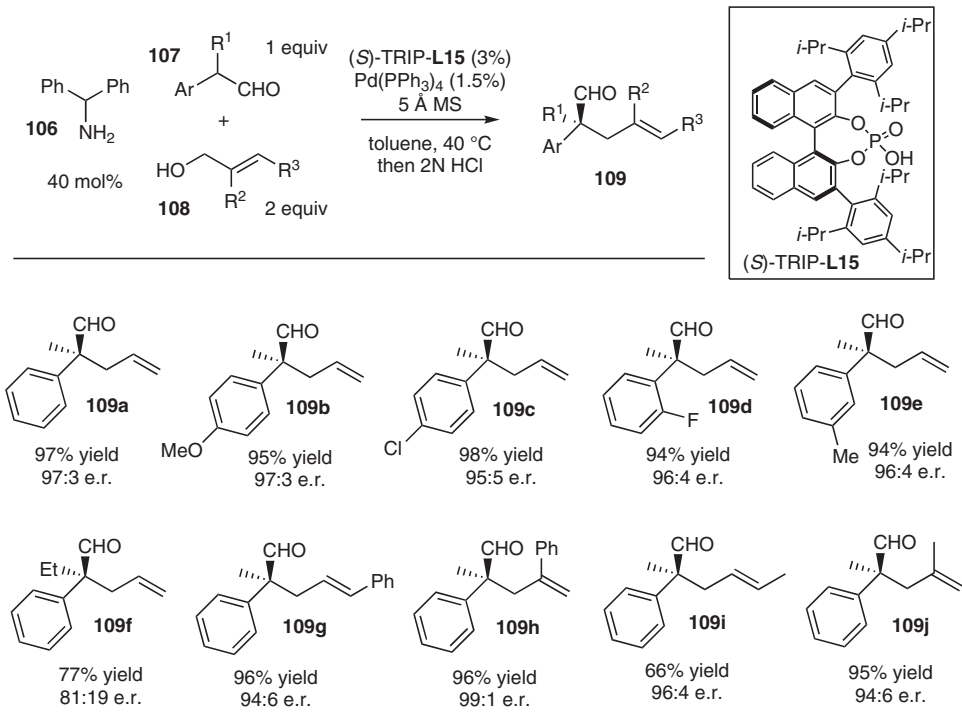

Scheme 35 The direct $\alpha$-allylation of $\alpha$-arylpropanals with allylic alcohols

Steric elements that result in high geometric control of the transiently formed chiral enamine were invoked to account for the stereoselectivity observed (Scheme 36a), and chiral information is transferred by hydrogen bonding by the enamine to the chiral phosphate (Scheme 36b). Since this species is counterion-paired with the cationic $\pi$-allylpalladium(II) species, asymmetric induction can be realized in the alkylation event. Additionally, it cannot be ruled out that the phosphoric acid acts as a ligand to the $\pi$-allylPd(II) species. Interestingly, under the reaction conditions, allyl alcohols can be used directly, due to the activation of the hydroxyl leaving group by the phosphoric acid (Scheme 36c).

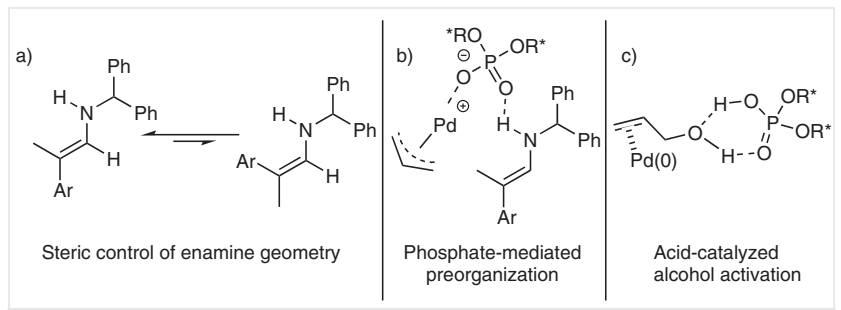

Scheme 36 Proposed mechanistic feature of triple catalysis

Another dual-catalytic approach was showcased by Ooi and co-workers for the $\alpha$-cinnamylation of $\alpha$-nitro esters (Scheme 37). ${ }^{35}$ Like the system developed by List and Jiang, the phosphine ligands employed in the method are achiral. However, a linked cationic ammonium functional group allows for self-assembly with a chiral BINOL counterion. A $\mathrm{Pd} /$ ligand ratio of $1: 2$ was used, as it was believed that a $C_{2^{-}}$ symmetric palladium complex would form upon cis-complexation of the phosphine ligands. Excellent yields and enantioselectivities were observed for the reaction when us- ing cinnamyl carbonate electrophiles 111, although no enantioselectivity was observed for the simple allyl system (112d).

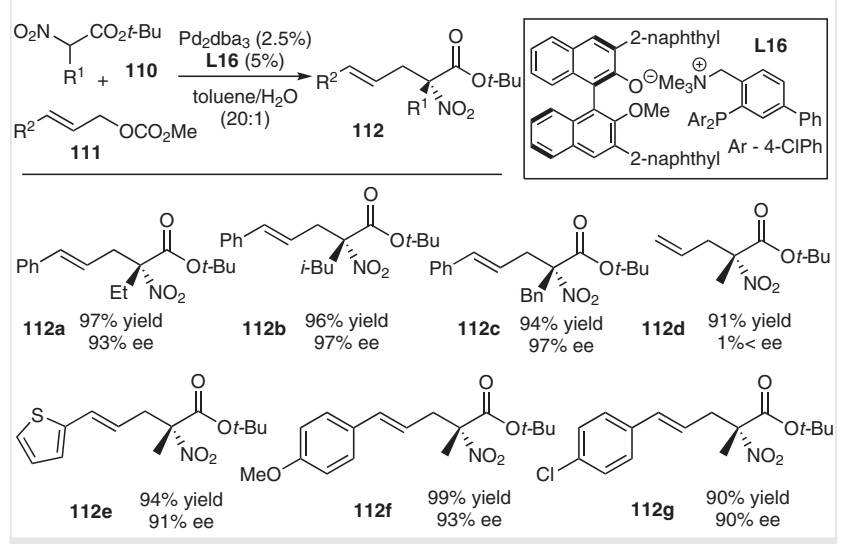

Scheme 37 Chiral counterion strategy for the cinnamylation of $\alpha$-nitro esters

The use of dual chiral palladium/chiral boron catalysis was applied to the $\alpha$-allylation of carboxylic acids (Scheme 38). ${ }^{36} \mathrm{~A}$ chiral boron species is generated by chelation of a boron Lewis acid with the chiral amino acid catalyst $\mathbf{L 1 8}$. Upon ionization of the allyl ester by the chiral palladium species (L17), a carboxylate ene-diolate species is readily formed, presumably due to the Lewis acidity of the coordinated boron catalyst and the presence of DBU as base. Although the enolates of carboxylic acids possess no geometry, the large steric differences of the $\alpha$-aryl substituents render the two enantiotopic faces of the nucleophile sufficiently distinguishable. The ability to use two chiral catalysts enables excellent enantioselectivity for both allyl and 

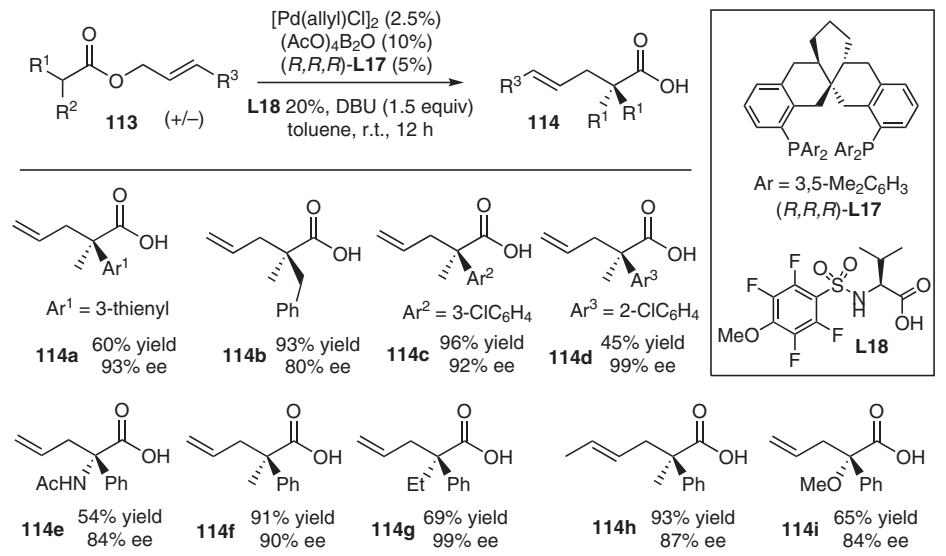

Scheme 38 Select examples in chiral Pd-AAA/chiral borane-catalyzed $\alpha$-allylation of carboxylic acids

3-substituted allyl systems. The scope of the reaction was largely limited to $\alpha$-aryl substrates, although and $\alpha$-benzyl substrate gave $\mathbf{1 1 4 b}$ with $80 \%$ ee.

The DAAA of cyclic $\alpha$-fluoro- $\beta$-keto esters proceeds with high enantioselectivity. ${ }^{37}$ Acyclic systems afforded products with high efficiency, although the enantioselectivities were low. More promising enantioselectivities were obtained when generating geometrically pure $(Z)$-lithium enolates (Scheme 39). ${ }^{38}$ These species were obtained by deprotonation of $\alpha$-fluoropropiophenones by LiHMDS at 0 ${ }^{\circ} \mathrm{C}$, and the transient species were subjected to Pd-AAA conditions to provide $\alpha$-allyl- $\alpha$-fluoropropiophenones with $60-90 \%$ ee.

\subsection{Decarboxylative Allylic Alkylation Strategies}

Unlike intermolecular allylic alkylation reactions, Pdcatalyzed decarboxylative allylic alkylations occur via a largely unimolecular reaction pathway (Scheme 40). ${ }^{39}$ That is, upon ionization of an allyl moiety, the Pd- $\pi$-allyl species is counterion-paired to its pronucleophile. Upon a decarboxylation event, alkylation occurs via an outer-sphere attack of the nucleophile on the reactive $\mathrm{Pd}-\pi$-allyl species, effectively furnishing the desired product and the regenerated chiral $\operatorname{Pd}(0)$ species.

The question of whether this reaction occurs via an inner- or outer-sphere mechanism is complicated by differences in the experimental outcomes of these reactions and the computed lowest energy pathway ${ }^{40}$ It is worth noting that computational work is for phosphino-oxazoline (PHOX) ligands, and experimental work is with structurally different bisphosphino Trost ligands. Experimental work showed that enol carbonate $\mathbf{1 1 8}$ underwent Pd-DAAA with kinetic resolution of the enantiomeric starting material (Scheme 41). The alkylation product $\mathbf{1 1 9}$ was formed with net retention of the stereochemistry, indicating an outersphere mechanism.

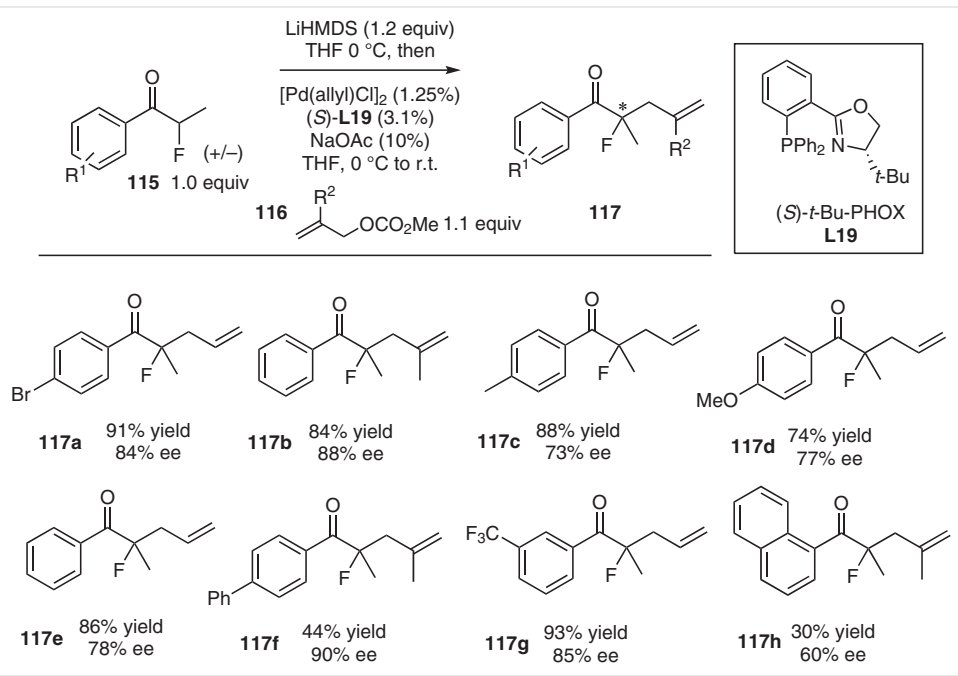

Scheme 39 Pd-AAA of $\alpha$-fluoropropiophenones 

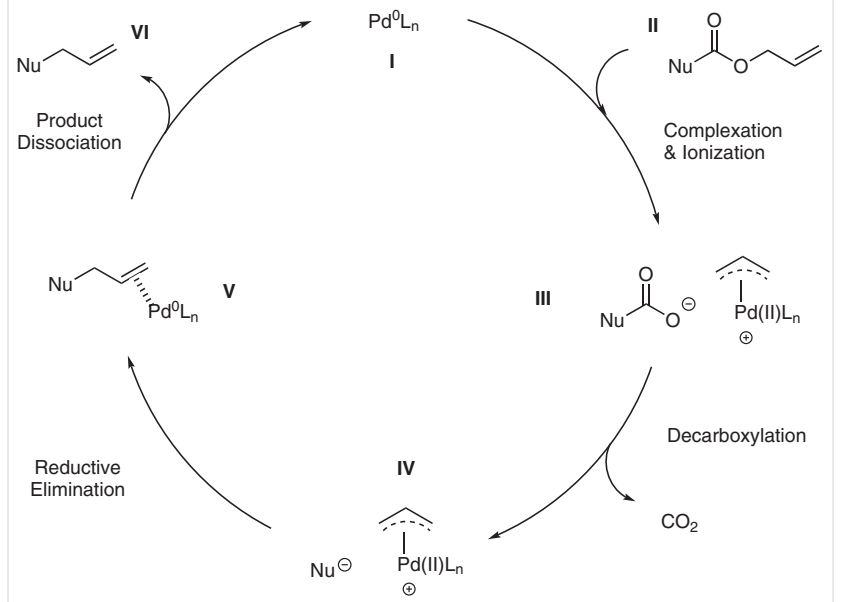

Scheme 40 Mechanism of the Pd-catalyzed decarboxylative allylic alkylation

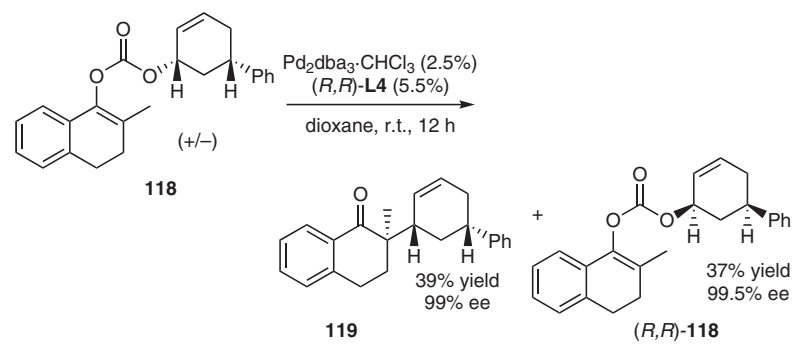

Scheme 41 Experimental evidence for an outer-sphere mechanism

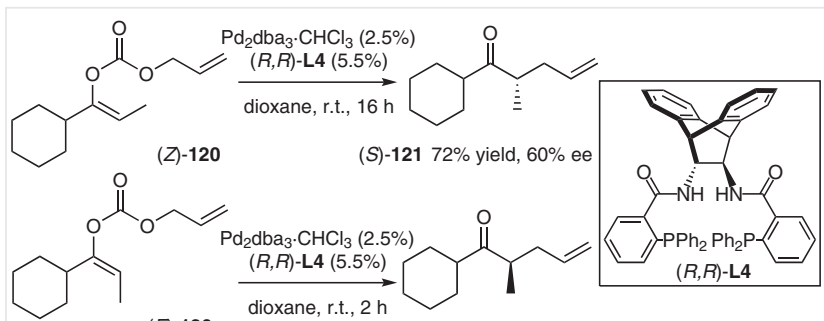

$(E)-120$

(R)-121 $94 \%$ yield, $97 \%$ ee

Scheme 42 Enantiodivergent allylations of (E)- and (Z)-enol carbonates

It was observed by the Trost group in work on the $\alpha$-allylation of acyclic ketones that control of the enolate geometry was crucial for high asymmetric induction (Scheme
42). ${ }^{41}$ It was shown that opposing enolate geometries diverged to opposite enantiomers of product, with matched and mismatched cases. This problem was easily overcome in the case of $\alpha$-tertiary ketone formation, since either enolate isomer could be synthesized by judicious choice of base. However, the synthesis of acyclic tetrasubstituted stereocenters would prove more difficult, due in large part to the small steric differences in the $\alpha$-substituents.

The Trost group developed Pd-DAAA reactions for the synthesis of acyclic tetrasubstituted stereocenters by the synthesis of protected $\alpha$-tertiary hydroxyaldehydes. ${ }^{42}$ The allyl carbonate precursors were synthesized with high geometric purity (Scheme 43). A highly flexible route to substrates allowed for $\alpha$-hydroxy 122 or $\alpha$-bromo ketones $\mathbf{1 2 4}$ to be used as substrates. Either regioisomer could be synthesized using hard or soft enolization conditions. Under soft enolization using TBSOTf and triethylamine, acyl transfer was suppressed, presumably due to the absence of any enolate formed, and 127a was isolated with high regioselectivity. Under hard enolization with sodium hexamethyldisilazanide, acyl transfer occurs to form the more stable aldehyde enolate. Trapping with $\mathrm{TBSCl}$ allows for synthesis of the opposite regioisomer 128a.

A DAAA reaction proceeds smoothly with high regioand enantioselectivity when the alcohol protecting group can undergo alkoxide transfer (Scheme 44). The process was found to be regioconvergent; that is, either regioisomeric starting material afforded the tertiary aldehyde product with nearly identical enantioselectivities. When an alkoxide transfer is not required (substrate 127a), the product was formed in 15 minutes in 93\% yield compared to a 1 hour reaction for the regioisomeric enol carbonate 128a.

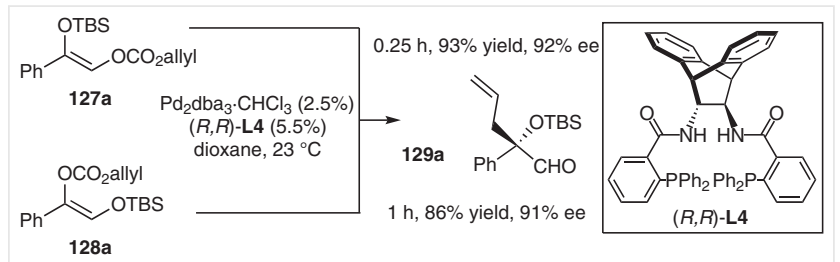

Scheme 44 A regioconvergent Pd-DAAA strategy toward $\alpha$-tertiary hydroxyaldehydes

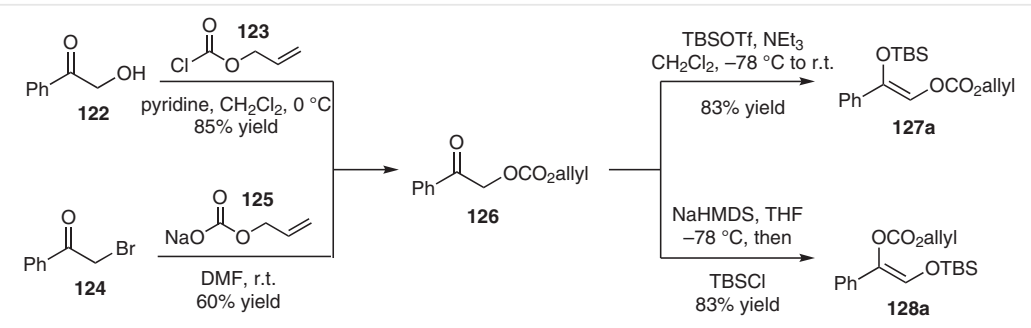

Scheme 43 An efficient regiodivergent synthesis of Pd-DAAA substrates 
The substrate scope revealed aromatic, vinyl, and alkynyl substituents provided the product with high enantioselectivity (Scheme 45). High yields and a rapid reaction rate were achieved by employing substrates 127 with a tertbutyldimethylsiloxy group at the benzylic position, as these substrates undergo Pd-AAA without silyl transfer. Additionally, decarboxylation likely occurs more rapidly with these regioisomeric substrates, since the resulting aldehyde enolate is more stabilized than the initially formed ketone enolate when using the regioisomeric substrate.

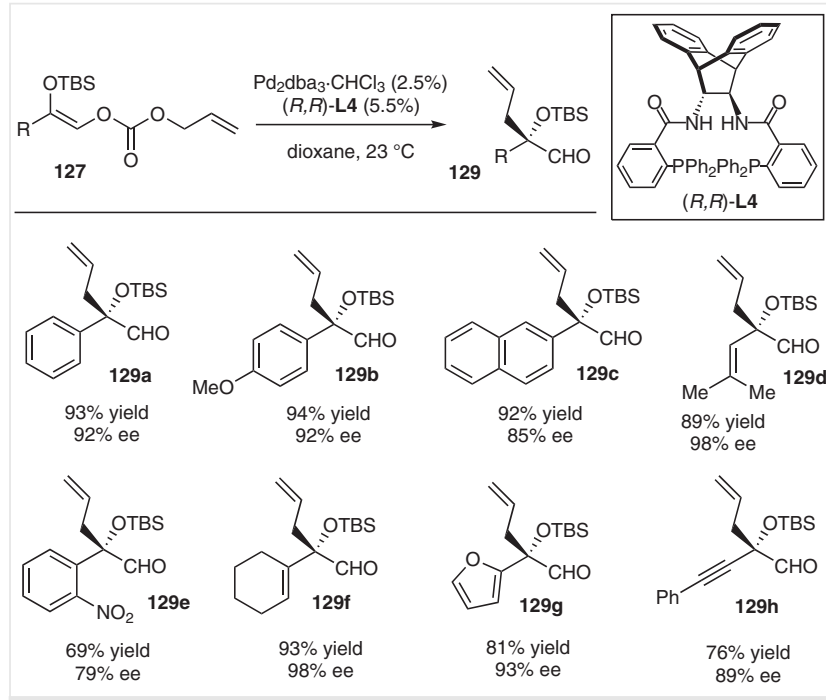

Scheme 45 A Pd-DAAA strategy toward $\alpha$-tertiary hydroxyaldehydes

This strategy was applied to the synthesis of a protected $\alpha$-hydroxy ketone 132 (Scheme 46). Displacement of the alkyl bromide 130 occurred smoothly in 87\% yield. Under hard enolization conditions, acyl transfer was not observed due to the trans relationship of the oxygen atoms. This isomer 131 was observed to be the major one, and it was separated from the minor isomeric products in $67 \%$ yield. The Pd-DAAA proceeded smoothly with regiospecificity in $94 \%$ yield and $80 \%$ ee.

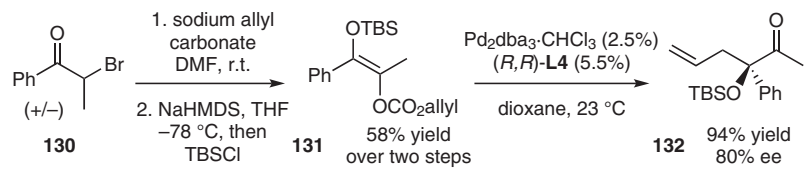

Scheme 46 Synthesis and reaction of ketone-derived $\alpha$-alkoxy enol carbonate

Additionally, electrophiles bearing stereochemistry could be subjected to the reaction conditions to produce alkylation products with high diastereoselectivity. This strategy was applied to the formal synthesis of (S)-oxybutynin (Scheme 47). The sodium carbonate of $\mathbf{1 3 3}$ was formed by treatment with sodium hydride, followed by carbon dioxide capture. The transiently formed species was then treated with 2-bromoacetophenone and was subsequently converted into DAAA substrate $\mathbf{1 3 5}$ by regioselective silylation. Although the starting enol carbonate $\mathbf{1 3 5}$ existed as a mixture of enantiomers, the stereochemistry about the electrophile was lost upon ionization, as the $\pi$-allyl species becomes symmetrical. The DAAA reaction proceeded smoothly in 18 hours to afford the hydroxyaldehyde $\mathbf{1 3 6}$ in $99 \%$ yield and 11:1 d.r. For substrate 135, the tert-butyldimethylsilyl protecting group transfer occurred efficiently, as indicated by the high yield in the DAAA reaction. Hydrogenation of the olefin afforded product 137 with $84 \%$ ee, reflecting the stereoselectivity about the tetrasubstituted carbon. Upon desilylation of $\mathbf{1 3 7}$ and Pinnick oxidation, hydroxy acid 139 was obtained as a single isomer after a single recrystallization, completing the formal synthesis of (S)-oxybutynin.

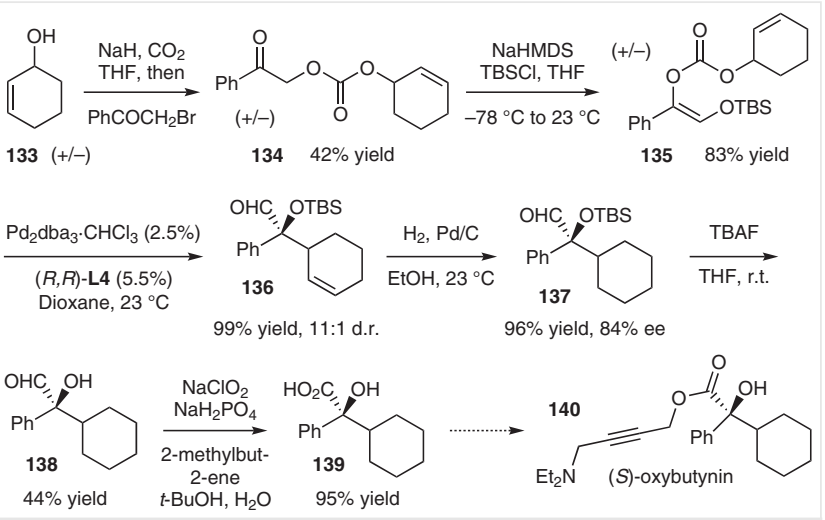

Scheme 47 Formal synthesis of (S)-oxybutynin by Pd-DAAA

A method for the synthesis of acyclic quaternary stereocenters by DAAA was investigated by Tunge and Ariyarathna. ${ }^{43}$ Racemic 141 was used with the hope that stereoinduction would be observed, even in the absence of enolate control (Scheme 48). In this system, the two $\alpha$-substituents are of considerable steric difference, and it could be imagined that this could result in stereocontrol of the formed enolate. Under conditions of catalyst control, only modest enantioselectivity could be observed, with Trost Ligand $\mathbf{L} \mathbf{4}$ affording the product with the highest enantioselectivity.

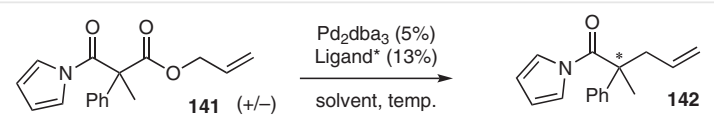

\begin{tabular}{|cccccc|}
\hline Entry & Ligand & Solvent & Temp ${ }^{\circ} \mathrm{C}$ & $\%$ Yield & $\%$ ee \\
\hline 1 & Quinap L22 & benzene & 25 & 93 & 11 \\
2 & $t$-Bu-PHOX-L19 & benzene & 25 & 97 & 5 \\
3 & Trost L4 & THF & -40 & - & 24 \\
4 & Trost L4 & DME & -40 & - & 20 \\
5 & Trost L4 & toluene & -40 & 90 & 49 \\
\hline
\end{tabular}

Scheme 48 Synthesis of quaternary stereocenters by Pd-DAAA of acyclic allyl $\beta$-oxo esters 
Additionally, a series of chiral auxiliary containing substrates 143 were employed as mixtures of diastereomers at the $\alpha$-carbonyl position (Scheme 49). Products were formed with some level of stereoinduction observed, and one auxiliary proved useful for recrystallization of the product in diastereomerically pure form.

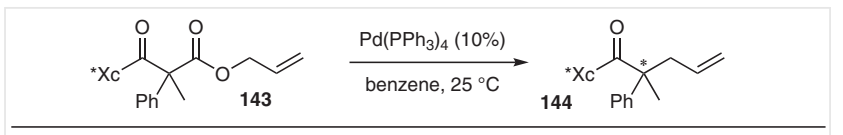

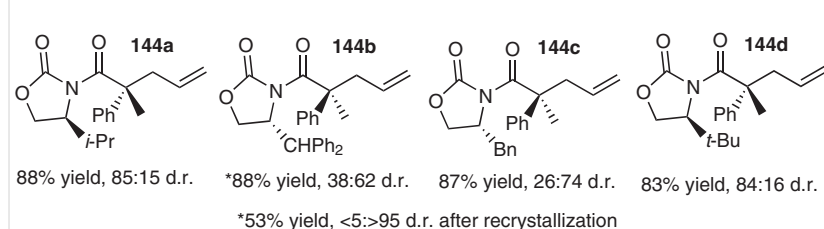

Scheme 49 Auxiliary approach for the Pd-DAA of acyclic allyl $\beta$-oxo esters

A more elaborate method of synthesizing geometrically defined enolates was developed by Marek and co-workers. ${ }^{44}$ An auxiliary-containing ynamide was carbometallated and oxidized to give geometrically pure enolates. This work was originally employed in aldol reactions; however, Starkov, Marek, Stoltz, and co-workers demonstrated that the transiently formed enolate can be successfully trapped as the enol carbonate (Scheme 50). ${ }^{45}$ Two protocols were developed for this reaction, due to limitations in substrate scope using a one-pot method when employing acyclic carbamate substrates. In the second method (Scheme 50b), the iodo enamide 149 was lithiated with $t$-BuLi, and the enol carbonate $\mathbf{1 5 0}$ was isolated with geometric purity after oxidation and acylation.
Optimization with a variety of PHOX and Trost-style ligands revealed electron-deficient Trost ligand $\mathbf{L 6}$ bearing the anthracene-9,10-diamine backbone provided the product with the highest enantioselectivity (Scheme 51). Substrate 151a was shown to provide 152a with higher enantioselectivity compared to substrates bearing an oxazolidinone.

The subsequent Pd-DAAA reaction provided allylation products with high enantioselectivity, even in cases where the two $\alpha$-substituents are of similar steric bulk (Scheme 52). This likely indicates that the chiral catalyst recognizes the steric and electronic differences of the enolate oxygen and the achiral auxiliary as opposed to the differentiation of the $\alpha$-substituents. A two-step allylation/cross-metathesis protocol was employed to better facilitate assay of the enantioselectivity. The acrylate moiety provided products 153 with higher differentiability of substituents and better absorptivity for UV detection.

For substrates bearing two $\alpha$-substituents with considerable steric difference (i.e., aryl vs. alkyl), high enantioselectivity can be achieved for aryl ketones (Scheme 53). ${ }^{46}$ Using a protocol developed for the synthesis of analogous enol tosylates, ${ }^{47}$ enol carbonate 155a was synthesized with $(E)$ selectivity. Solvent optimization with an electron-deficient PHOX ligand L20 provided high enantioselectivity with a mixed hexane/toluene solvent system.

Although high geometric control could be achieved in the enol carbonate formation, it was observed that this was unnecessary when employing the PHOX L20, as similar levels of enantioselectivity were observed for a mixture of enolate isomers and $\beta$-keto ester 157 (Scheme 54). However, high levels of enantioselectivity ( $86 \%$ ee) were observed when using Trost ligand $\mathbf{L} \mathbf{4}$ for the geometrically defined enol carbonate under the optimized conditions for the

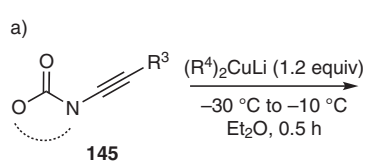

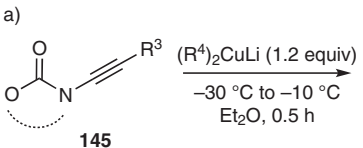

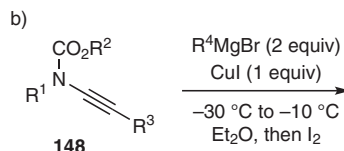

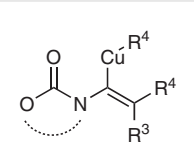

146

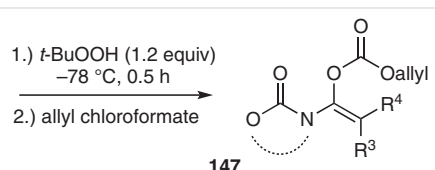

147

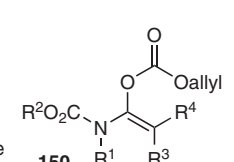

Scheme 50 One-pot carbometalation/oxidation/acylation synthesis of tetrasubstituted amide enol carbonates and two-pot carbometalation/iodination followed by lithiation/oxidation/acylation

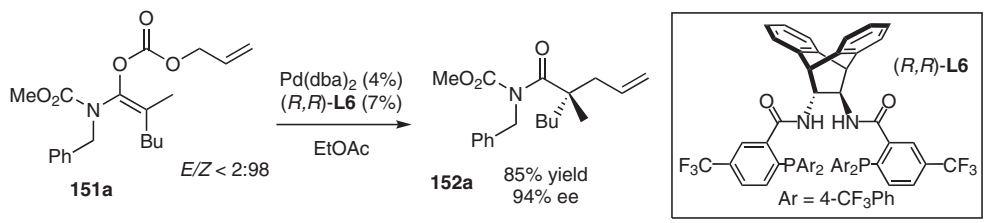

Scheme 51 Optimized substrate for Pd-DAAA of tetrasubstituted amide enol carbonates 


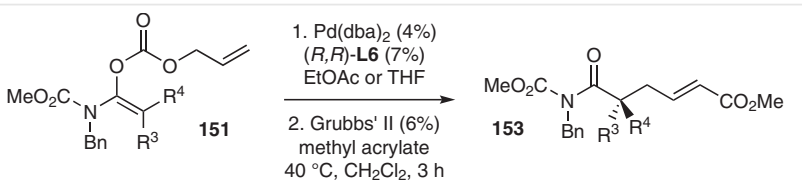

$$
\begin{aligned}
& \text {-hex } \\
& \begin{array}{c}
69 \% \& 84 \% \text { yield } \\
94 \% \text { ee }
\end{array} \\
& \text { TBSO } \\
& \text { (153c } \\
& \text {-Bü } \\
& \begin{array}{c}
76 \% \& 79 \% \text { yield } \\
94 \% \text { ee }
\end{array} \\
& \begin{array}{c}
77 \% \& 78 \% \text { yield } \\
76 \% \text { ee }
\end{array} \\
& \text {-hex }
\end{aligned}
$$

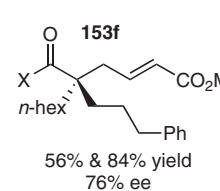

Scheme 52 Substrate scope of Pd-DAAA of tetrasubstituted amide enol carbonates
$\underset{\mathrm{Ph}^{(+/-)}}{\stackrel{\mathrm{LiHMDS}, \mathrm{Me}_{2} \mathrm{NEt}}{\stackrel{\text { toluene, } 23^{\circ} \mathrm{C} \text {, then }}{\text { allyl chloroformate }}}}$

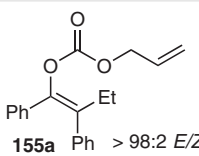

$\mathrm{Ar}$
$\mathrm{A}=$ alkyl

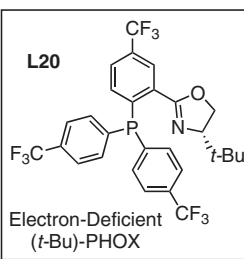

95-99\% yield

21 examples
Scheme 53 A Pd-DAAA of stereodefined tetrasubstituted 1,2-diaryl enol carbonates

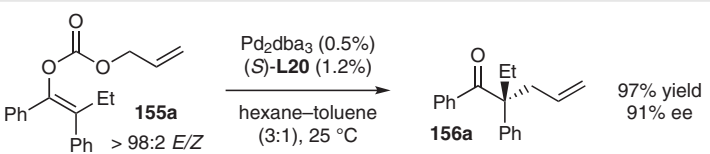

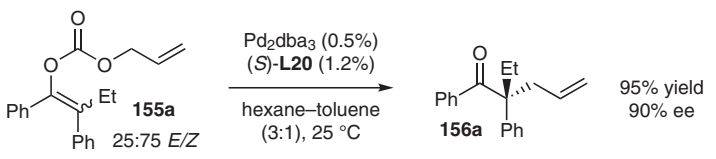

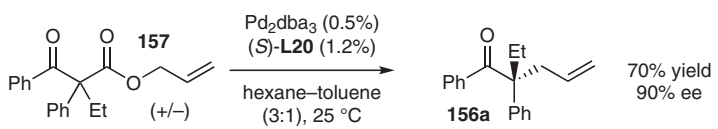

Scheme 54 Independence of enolate geometry on enantioselectivity for an electron-deficient ( $t$-Bu)-PHOX ligand
PHOX system, but selectivity (50\% ee) was diminished when using a mixture of isomers. It was speculated that rapid $\mathrm{C}-\mathrm{O}$ equilibration of the palladium(II) enolate may account for this effect when using the PHOX system. Potentially, optimization with the PHOX ligand resulted in conditions where the facial differentiability of the $\alpha$-substituents dictates the stereochemical outcome of the reaction.

A reaction involving the DAAA of $\alpha$-acetamido- $\beta$-keto esters 158 has been described for an acyclic system (Scheme 55). ${ }^{48}$ Interestingly, with little optimization, high levels of enantioselectivity were realized in this reaction, albeit for a limited substrate scope. Potentially, there is control of the enolate geometry due to hydrogen bonding between the amide hydrogen and the transient enolate ion. Phenol and naphthol were found to improve the enantioselectivity, although the origin of this effect is not well understood.

A Pd-AAA of nitroalkanes has been described by Shibasaki and co-workers (Scheme 56). ${ }^{49}$ Although most of the reactions described in the method involve stereocontrol on the electrophile, a single example of Pd-AAA with a racemic secondary nitroalkane 160 and allyl carbonate 161 was reported, albeit with low enantioselectivity.

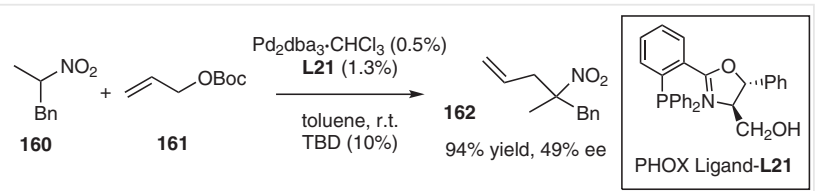

Scheme 56 Asymmetric allylation for the synthesis of $\alpha$-tertiary nitroalkanes

\section{Temporary Cyclic Pronucleophiles}

\subsection{Reactions of Azlactones}

Alkylation of azlactones directly furnishes products with cyclic tertiary amino functionality, and the subsequent hydrolysis of the products has proven useful for producing acyclic $\alpha$-tertiary amino acids (Scheme 57). This provides an efficient method for the synthesis of unnatural amino acids, as the synthesis and elaboration of azlactones can be readily accomplished using commercially available
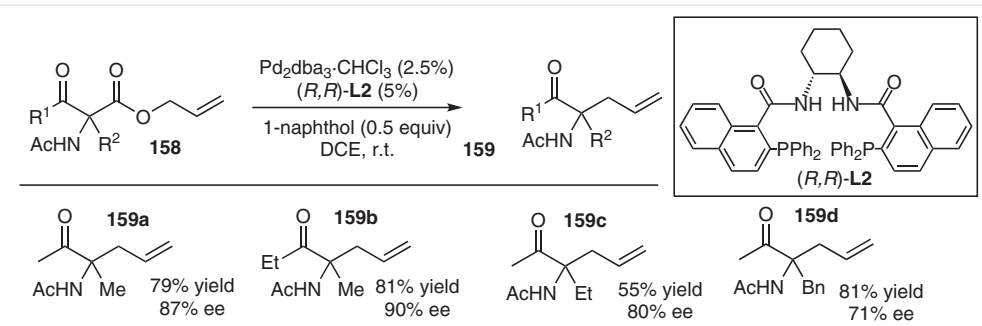

Scheme 55 Pd-DAAA of $\alpha$-acetamido- $\beta$-keto esters 
amino acids. Additionally, the identity of the carboxylic acid template may serve as a point for reaction optimization.

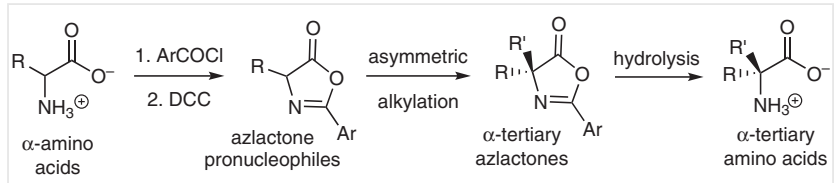

Scheme 57 Azlactones as precursors to acyclic $\alpha$-tertiary amino acids

The Trost group has shown a breadth of Pd-AAA reactions with azlactones for a variety of allyl electrophiles. ${ }^{50}$ Impressively, some of the first asymmetric Pd-catalyzed benzylation reactions were developed using azlactones as pronucleophiles. ${ }^{51}$ For electron-deficient electrophiles $\mathbf{1 6 3}$, a diphenyl phosphate leaving group in conjunction with elevated temperatures allowed for the difficult ionization to occur (Scheme 58).

In the case of electron-rich benzyl electrophiles 166, the diethyl phosphate leaving group proved sufficient at ambient temperatures. This methodology was used in a short asymmetric synthesis of $\alpha$-methyl-D-DOPA (Scheme 59a). Under conditions for the asymmetric benzylation of electron-rich benzylic phosphates, the key alkylation step afforded $\alpha$-tertiary azlactone 167 in $83 \%$ yield and $90 \%$ ee. The desired acyclic target $\mathbf{1 6 8}$ was synthesized in 96\% yield by hydrolysis of the azlactone. Conveniently, the methylenedioxy group was hydrolyzed under these conditions. Additionally, triflic acid hydrolysis in the presence of methanol allows for access to the acyclic protected amino acids $\mathbf{1 7 1}$ (Scheme 59b).

Similarly, allyl electrophiles allow for the installation of a functional group handle for synthetic modification (Scheme 60).50a Interestingly, symmetrical allyl and 2-methallyl electrophiles yielded products with low enantioselectivity. However, unsymmetrical 3-substituted electrophiles and prenyl electrophiles afforded the $\alpha$-tertiary alkylated products with high enantioselectivity. It is important to note that prenyl and cinnamyl electrophiles produce alkylation products with an opposite sense of chirality.
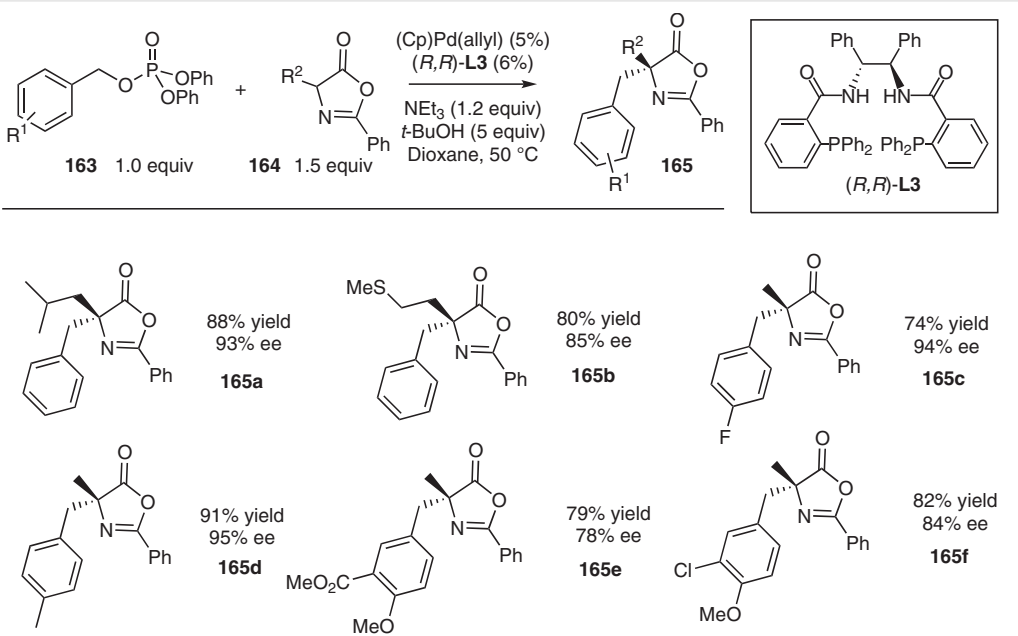

Scheme 58 Pd-catalyzed benzylation of azlactones
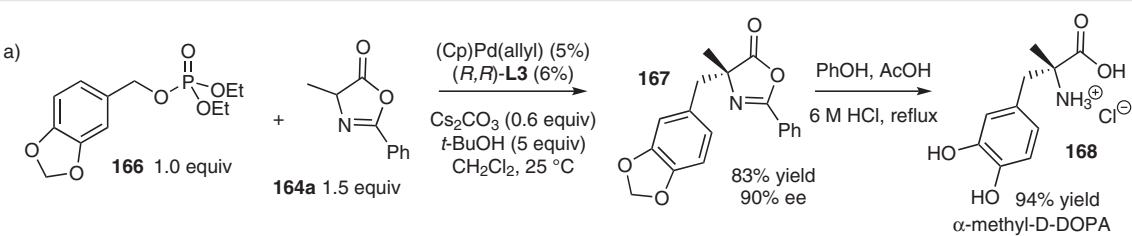

b)<smiles>CCOP(=O)(OC)OCc1ccc(OC)cc1</smiles><smiles>CC1N=C(c2ccccc2)OC1=O</smiles>
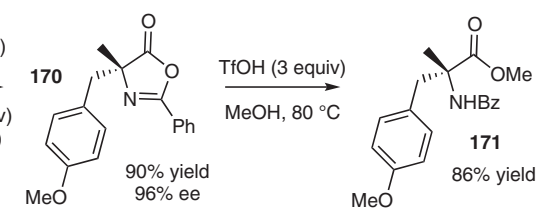

Scheme 59 Pd-catalyzed benzylation strategy for the synthesis of $\alpha$-methyl-D-DOPA and benzylation strategy toward acyclic $\alpha$-tertiary amino acids 
a)

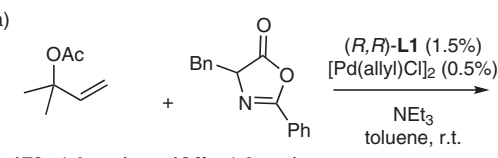

1721.0 equiv $164 \mathrm{~b} \quad 1.2$ equiv

b)<smiles>CC(=O)OC/C=C/c1ccccc1</smiles>

1751.0 equiv

164b 2.25 equiv

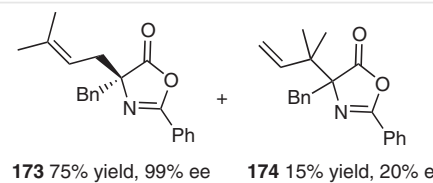

(1)

$17691 \%$ yield, $90 \%$ ee

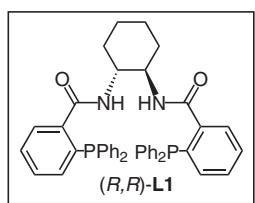

Scheme 60 Enantiodivergent alkylation with reverse prenyl and cinnamyl electrophiles

For unsymmetrical allyl systems, diastereomeric $\pi$-allyl complexes are possible (Scheme 61). This feature likely dictates a distinct mode of attack by the nucleophile, and in the case of azlactones, this trajectory of approach results in better recognition of the prochiral faces of the incoming nucleophile. When the linear product is favored, it can be seen that by placing the 3-allyl substituent under the less hindered flap (Scheme 61a), nucleophilic attack occurs at the terminus where chiral information is better relayed from the metal center. a)

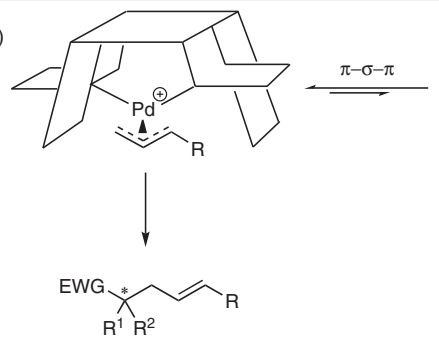

high enantioselectivity

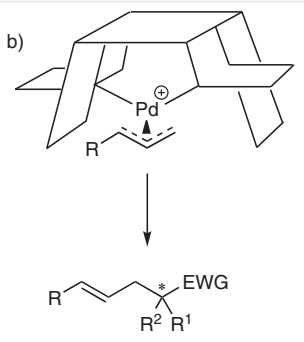

low enantioselectivity
Scheme 61 Rationale for higher enantioselectivity for alkylation of 3-substituted electrophiles
In addition to reactions that form stereochemistry on the nucleophile, the Trost group has utilized this transformation for simultaneous stereoinduction on the electrophilic partner (Scheme 62). ${ }^{50 \mathrm{~b}}$ A Pd-AAA with cyclic electrophile $\mathbf{1 7 7}$ afforded the product $\mathbf{1 7 8}$ with high diastereoand enantioselectivity. The remarkably high level of enantioselectivity observed in this reaction is likely a result of statistical enrichment, since the $\operatorname{Pd}(0) /$ chiral ligand system has been shown to induce high levels of asymmetric induction on each partner independently.

A geminal diacetoxyallylic electrophile $\mathbf{1 7 9}$ was applied to the synthesis of sphingofungin $\mathrm{F}$ (Scheme 63). ${ }^{52}$ In this reaction, the stereochemistry on the electrophile results from selective ionization of enantiotopic leaving groups independent of the presence of the nucleophile. The stereochemistry on the azlactone in $\mathbf{1 8 0}$ was additionally obtained with high diastereoselectivity. The relative stereochemistry of the amino and acetoxy functional groups was strategically inverted in subsequent steps in the synthesis of sphingofungin $\mathrm{F}$.
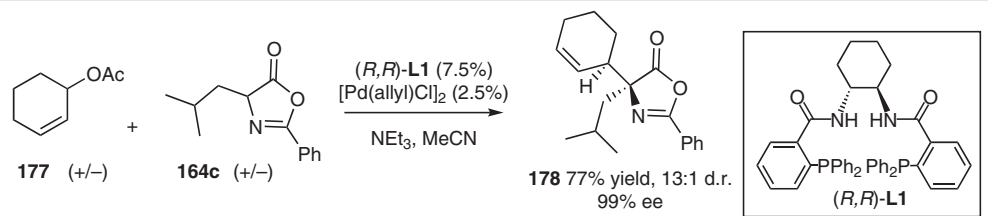

Scheme 62 Diastereo- and enantioselective Pd-AAA of azlactones with cyclic prochiral electrophiles

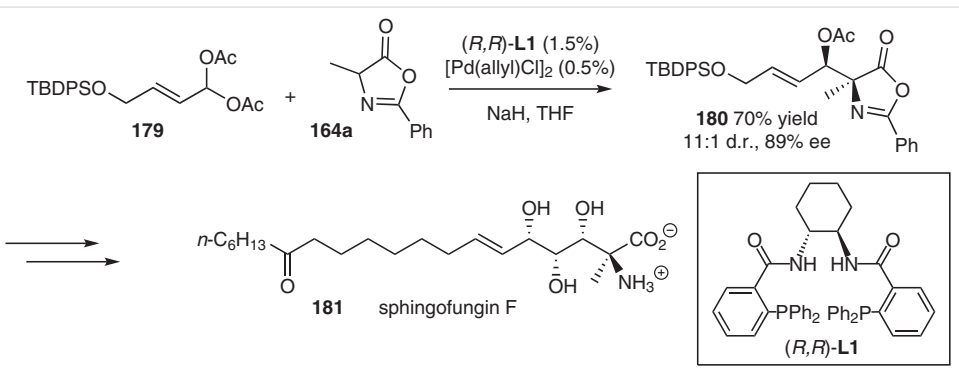

Scheme 63 A diastereo- and enantioselective synthesis of sphingofungin $F$ 


\subsection{Cyclic $\alpha$-Alkoxy-Bearing Substrates}

A similar strategy as that used for $\alpha$-tertiary amino acids could be envisioned for asymmetric $\alpha$-tertiary alcohol synthesis, whereby a cyclic template could serve to control enolate geometry (Scheme 64). The Stoltz group have shown that dioxanones 182 derived from 1,3-dihydroxyacetone can be used for this purpose. ${ }^{53}$
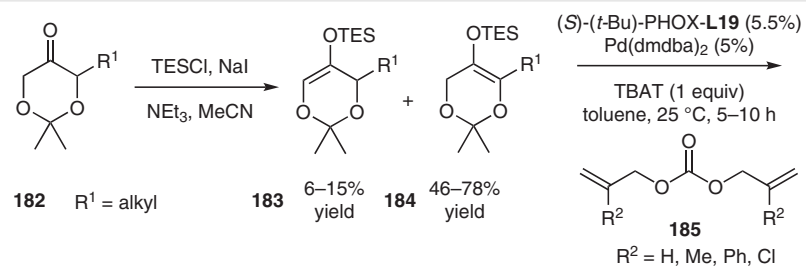

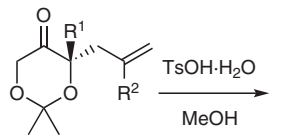

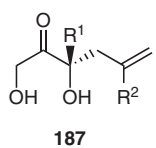

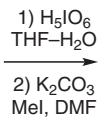

$18659-93 \%$ yield $80-90 \%$ yield $85-94 \%$ ee

Scheme 64 Acyclic $\alpha$-tertiary hydroxy ketones, acids, and esters from dioxanone

Alkylation of unsubstituted dioxanones, followed by silyl enol ether formation provided substrates 184 for allylic alkylation. The trimethylsilyl enol ethers proved too unstable; however, the regioisomeric triethylsilyl enol ethers $\mathbf{1 8 3}$ and 184 could be separated by silica gel chromatography. In the presence of TBAT as a desilylation reagent, allylation proceeded in high yield and enantioselectivity using symmetrical unsubstituted and 2-substituted allyl carbonates 185 as electrophiles. A 4-toluenesulfonic acid catalyzed hydrolysis of $\mathbf{1 8 6}$ in the presence of methanol gave the acyclic hydroxy ketone products 187 . Periodate cleavage, followed by esterification provided $\alpha$-tertiary hydroxyl esters $\mathbf{1 8 8}$. This method was used in an efficient synthesis of (+)-eucomic acid. ${ }^{54}$

A Pd-DAAA of 5- and 6-membered lactam precursors was developed by the Stoltz group (Scheme 65). ${ }^{55}$ An $\alpha$-hydroxy ester 191 was accessed by hydrolysis of the DAAA product 190 in the presence of catalytic methanol and sulfuric acid. ${ }^{56}$ The method additionally was also performed using a sulfur-containing lactam, an allyl 2-methyl-3-oxothiomorpholine-2-carboxylate, although derivatization of the product to the acyclic precursor was not demonstrated.

Likewise, thiopyranones were used for the synthesis of acyclic quaternary stereocenters (Scheme 66). ${ }^{57}$ Acylation of thiopyranone and subsequent alkylation of the resulting $\beta$-keto ester provides substrates 192 for Pd-DAAA. The reaction proceeds with high yield and enantioselectivity in most cases. Direct extrusion of the sulfur atom was attempted, but hydrogenation of the allyl olefin of 193a could not be avoided. A hydroboration/oxidation proved useful for avoiding this problem, as Raney nickel in ethanol afforded the desired acyclic $\alpha$-quaternary ketone 195 in 94\% yield over the sequence. Although this method represents an application of cyclic structure for creating acyclic stereocenters, it suffers from the drawback of being limited to the synthesis of $\alpha$-methyl ethyl ketones only.
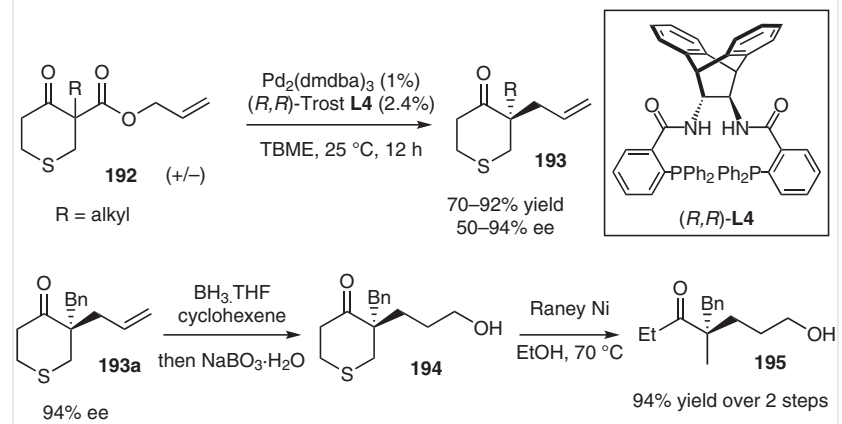

Scheme 66 Thiopyranones as precursors of acyclic quaternary stereocenters

\section{Allylic Alkylation with Other Metals}

The first reactions within the area of allylic alkylation to demonstrate stereocontrol in the synthesis of acyclic stereocenters were in Pd-AAA, followed by reactions in Mocatalyzed AAA; however, within the last few years, major advances have been made employing other metals, most notably rhodium and iridium. Copper-catalyzed allylic substitution reaction $5^{58}$ nicely complement methods with other metals due to the unique $S_{N} 2$ ' pathway and the ability to employ hard nucleophilic precursors. The structures of ligands used in Mo-, Ir-, and Rh-catalyzed AAA are shown in Figure 2.
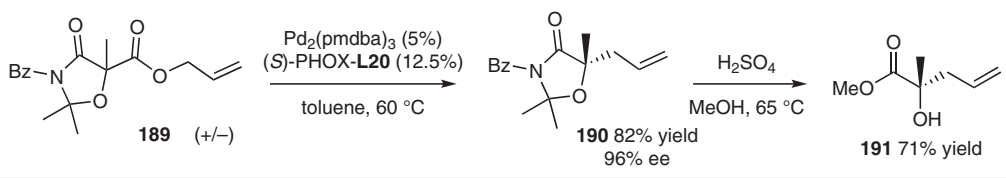

Scheme 65 Lactam precursor to $\alpha$-hydroxy tertiary esters 


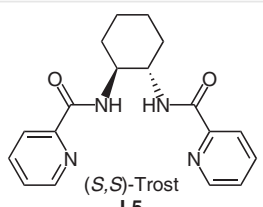

L5<smiles>C=CC1CC2CCN1C2[C@H](N)c1ccnc2ccccc12</smiles><smiles>COc1ccnc(C(=O)N[C@H]2CCCC[C@H]2NC(=O)c2cc(OC)ccn2)c1</smiles>

L23

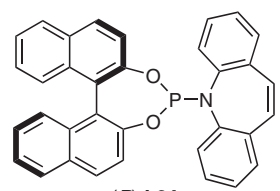

(R)-L24

Review

gure 2 Structures of ligands used in Mo-, Ir-, and Rh-catalyzed AAA

\subsection{Molybdenum-Catalyzed AAA}

The ability to selectively access branched allylic alkylation products is an attractive feature for creating stereochemistry on electrophilic partners. Among metals that typically afford branched products selectively (Mo and Ir), selectivity on the nucleophilic partner was first achieved in Mo-AAA for azlactones ${ }^{59}$ and oxindoles. ${ }^{60}$

In the case of branch-selective azlactone alkylation, ${ }^{58}$ the reaction proceeded in excellent yield as well as diastereo- and enantioselectivity (Scheme 67). Similar levels of yield and selectivity were observed when using a carbonate or phosphate leaving group; however, the use of lithium base was found to afford higher branch selectivity compared to sodium or potassium hexamethyldisilazanide. Additionally, adopting a one-pot protocol for hydrolysis of the azlactone afforded 197 in higher yield compared to the stepwise process.

The scope of the reaction showed the best results for cinnamyl methyl carbonate electrophile (197a-e), with slightly diminished enantioselectivities for heteroaromatic as well as 2-substituted phenyl systems (197f-j). High selectivity was achieved for aliphatic $\alpha$-substituents with varied substitution patterns. It is important to note that linear, achiral electrophiles 196 performed better than branched, racemic allylic carbonates, presumably due to slow $\pi-\sigma-\pi$ equilibration relative to nucleophilic attack. The mode of asymmetric induction on the electrophile therefore likely results from differentiation of the enantiotopic faces of the electrophile in olefin coordination and/or ionization.

With success using azlactones as precursors for acyclic $\alpha$-tertiary amino acids, the Trost group studied the isomeric oxalactims $\mathbf{1 9 8}^{61}$ as precursors to acyclic $\alpha$-tertiary alcohols (Scheme 68).

Indeed, these pronucleophiles undergo Mo-AAA with regio-, diastereo-, and enantioselectivity. In addition to the standard cinnamyl-type electrophiles, vinyl-substituted systems perform as well $(\mathbf{1 9 9 c}, \mathbf{d})$. An efficient hydrolysis of the products directly affords acyclic $\alpha$-tertiary hydroxy amides (Scheme 69).

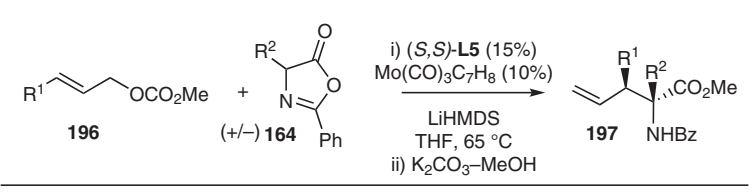

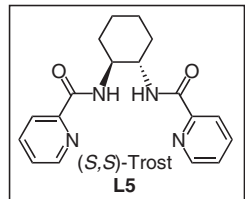

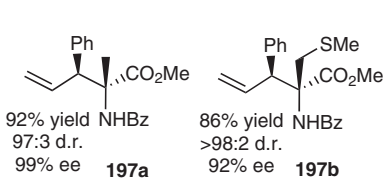

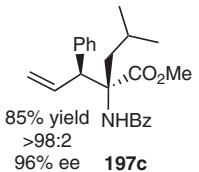

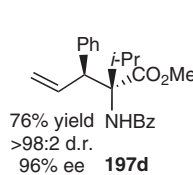

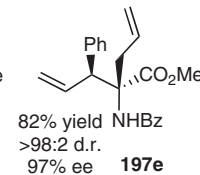

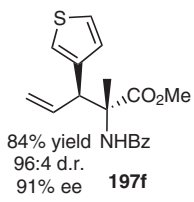
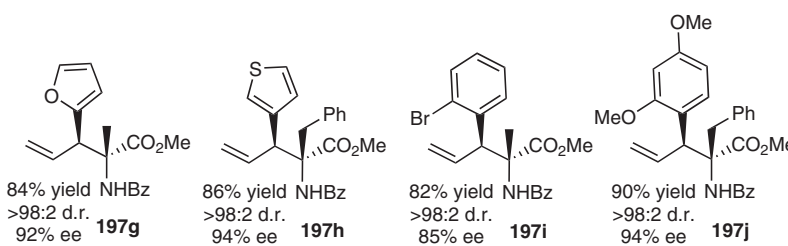

Scheme 67 One-pot Mo-catalyzed regio-, diastereo-, and enantioselective allylic alkylation of azlactones followed by hydrolysis 

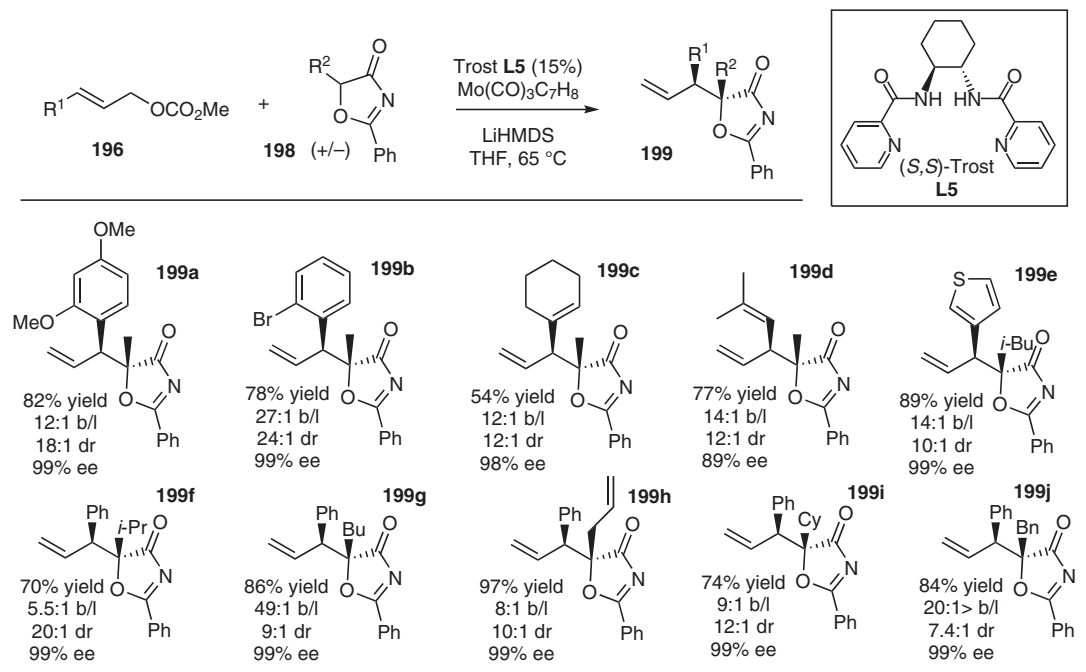

Scheme 68 Mo-catalyzed regio-, diastereo-, and enantioselective allylic alkylation with oxalactims

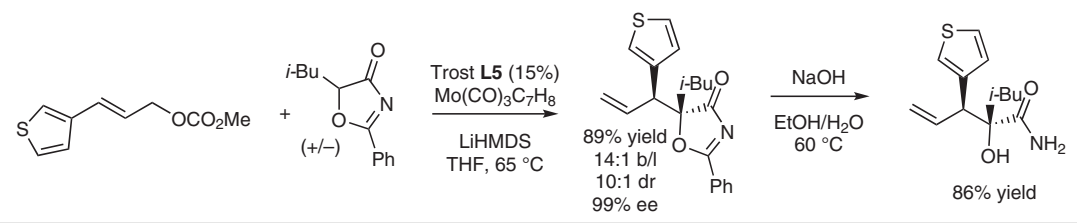

Scheme 69 Conversion of oxalactim into acyclic $\alpha$-tertiary hydroxy amides

The synthesis of acyclic quaternary stereocenters was achieved using $\alpha$-substituted $\alpha$-cyano esters 200 as pronucleophiles (Scheme 70). ${ }^{62}$ Interestingly, the process affords acyclic quaternary carbon products in excellent enantioselectivity in cases where the allyl electrophile bears no ste- reochemistry (201a,b). Both alkyl and aryl $\alpha$-substituents resulted in high regio-, diastereo-, and enantioselectivity. Additionally, $\alpha$-tertiary ether product $\mathbf{2 0 1 h}$ was accessed with good diastereo- and enantioselectivity.
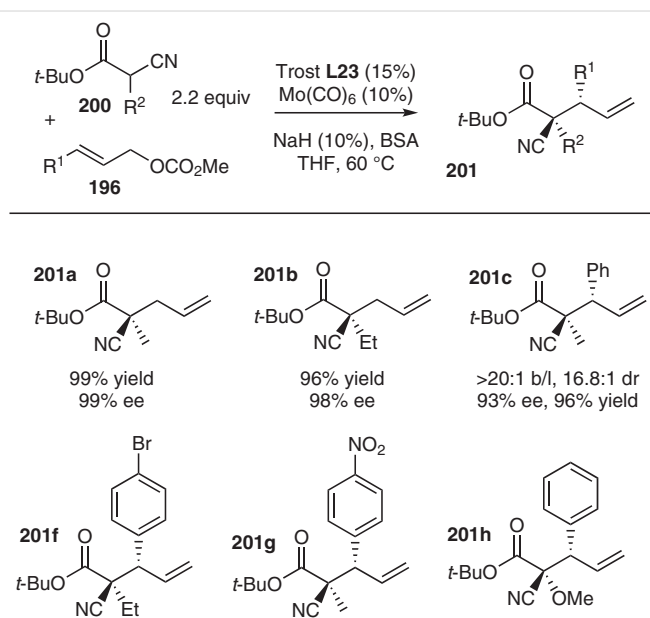
$>20: 1 \mathrm{~b} / \mathrm{l}, 13.7: 1 \mathrm{dr}$
$97 \%$ ee, $92 \%$ yield

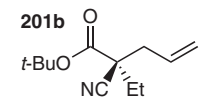

$96 \%$ yield $98 \%$ ee

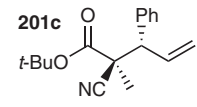

$>20: 1 \mathrm{~b} / \mathrm{l}, 16.8: 1 \mathrm{dr}$ $93 \%$ ee, $96 \%$ yield

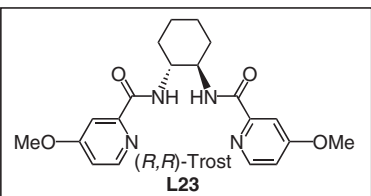

L23

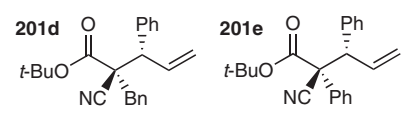

$>20: 1 \mathrm{~b} / \mathrm{l}, 29: 1 \mathrm{dr} \quad>20: 1 \mathrm{~b} / \mathrm{l}, 20: 1 \mathrm{dr}$ $98 \%$ ee, $93 \%$ yield $\quad 99 \%$ ee, $95 \%$ yield

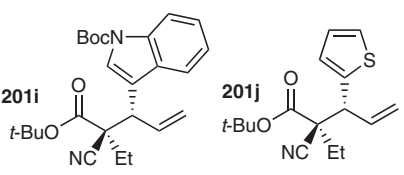

$>20: 1 \mathrm{~b} / \mathrm{l}, 11: 1 \mathrm{dr} \quad>20: 1 \mathrm{~b} / \mathrm{l}, 20: 1 \mathrm{dr}$
$97 \%$ ee, $99 \%$ yield

Scheme 70 Mo-catalyzed regio-, diastereo-, and enantioselective allylic alkylation of acyclic $\alpha$-cyano esters 


\subsection{Iridium-Catalyzed AAA}

In iridium-catalyzed allylic alkylation, the ability to control stereochemistry on the nucleophilic partner simultaneous to stereocontrol was first demonstrated by Takemoto and co-workers ${ }^{63}$ in 2003. Since that first report, enantioand diastereoselective Ir-AAA reactions have been reported for several systems. This topic has been reviewed elsewhere ${ }^{64}$ so we will focus on two systems that demonstrate the synthesis of acyclic quaternary carbons on the nucleophilic and electrophilic partners, respectively.

In an impressive display of enantio- and diastereodivergence, Carreira and co-workers (Scheme 71$)^{65}$ were able to demonstrate the ability to access all four stereoisomers in the $\alpha$-cinnamylation of aldehydes to afford vicinal acyclic quaternary and tertiary stereocenters. Borrowing from the success of dual-catalysis in Pd-AAA, they employed cinchona alkaloids with chiral phosphoramidite ligands. The pseudo-enantiomeric catalyst was employed to access the other diastereomer. Despite a small match-mismatch effect, all four diastereomers can be accessed in near perfect selectivity by this method.

The branch-selective Ir-AAA of trisubstituted cinnamyl electrophiles was demonstrated by the Stoltz group (Scheme 72). ${ }^{66}$ In this reaction, acyl anion equivalent 205 is used to allow for easy access to $\alpha$-aryl- $\alpha$-vinyl carbonyl compounds 207. This method demonstrates a new landmark in Ir-AAA, as more highly substituted electrophiles 206 have proven difficult in Ir-AAA. In a single operation, the acyl anion was cleaved to directly afford carboxylic acid
207. Additionally, conditions were developed to obtain esters and primary and secondary amides directly from the allylic alkylation products.

The reaction was limited in electrophile scope, as replacement of the methyl group with ethyl (207j), isopropyl, or butyl groups or the para- or mono-meta-substituted phenyl group with di-meta- (207i) or ortho-substituted phenyl groups (2071) resulted in lower, or no, reactivity, but not lower enantioselectivity. Additionally, excess electrophile over the acyl anion equivalent was required for high yields. Triethylborane proved to be crucial for reactivity, as no reaction proceeded in its absence, and lower yields were observed for lithium bromide as an additive. Presumably, triethylborane assists by Lewis acid activation in the otherwise difficult ionization reaction. The mode of asymmetric induction of this reaction is selective ionization from enantiotopic faces. This was demonstrated by observing no enantioselectivity when using the branched, racemic electrophile.

\subsection{Rhodium-Catalyzed AAA}

Exploiting the stereospecificity of the Rh-allylic alkylation, the Evans group was able to alkylate enantiopure tertiary allylic carbonates with regio- and stereospecificity (Scheme 73). ${ }^{67}$ An electron-deficient phosphite ligand was found to afford the product with highest enantiospecificity (denoted as es) compared to more electron-neutral phosphite ligands. ${ }^{68}$ All ligands screened showed complete regiospecificity in the reaction. It was reasoned that the elec-
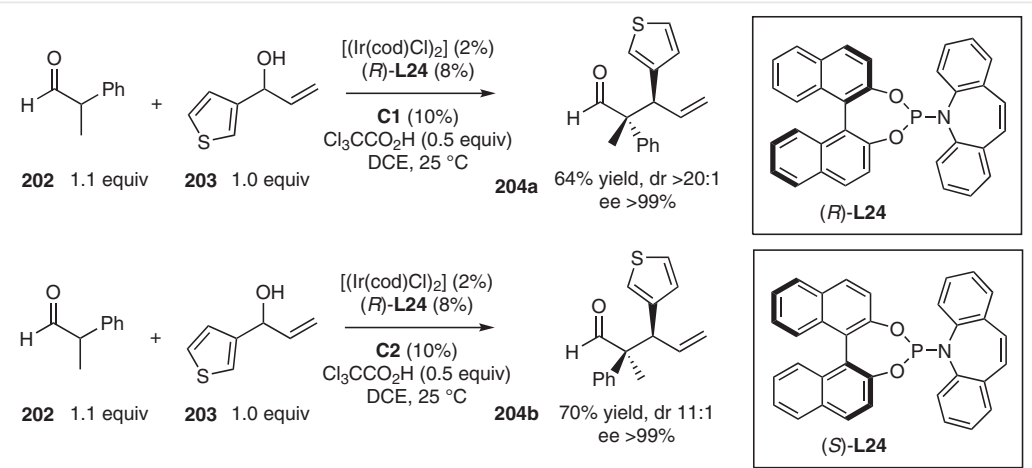

2021.1 equiv

2031.0 equiv $\mathrm{DCE}, 25^{\circ} \mathrm{C}$
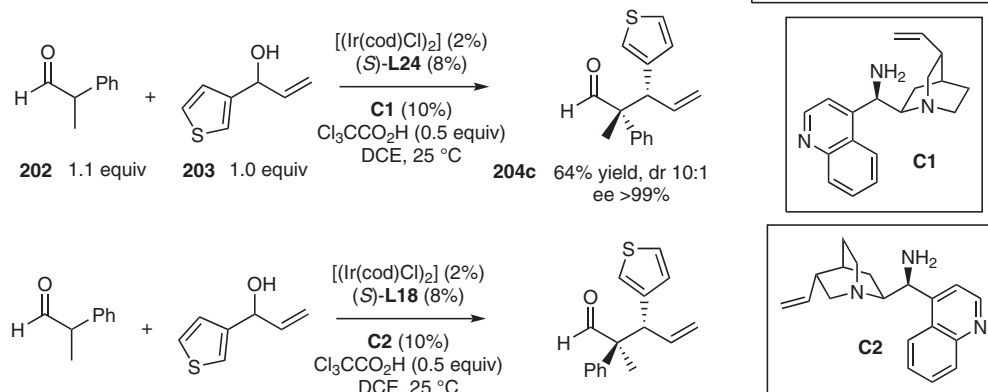

2021.1 equiv 2031.0 equiv DCE, $25^{\circ} \mathrm{C}$
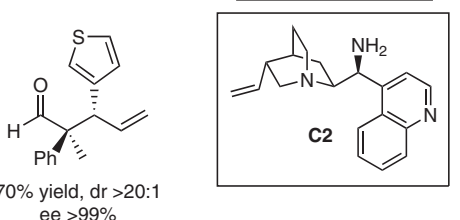

204d $70 \%$ yield, $d r>20$
ee $>99 \%$

Scheme 71 Regio-, diastereo-, and enantioselective $\alpha$-cinnamylation of aldehydes by dual chiral amine/chiral iridium catalysis 


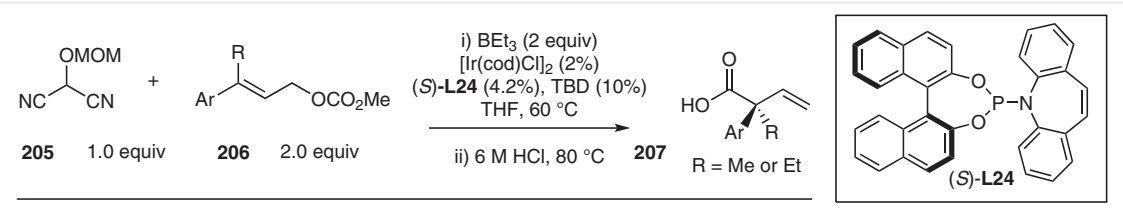

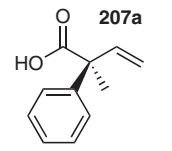

$77 \%$ yield
$95 \%$ ee

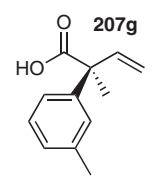

${ }^{*} 68 \%$ yield
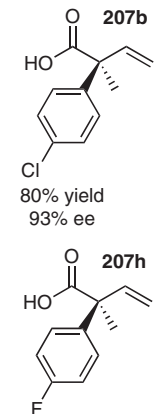

$90 \%$ yield
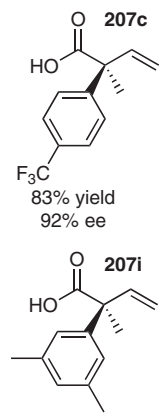

${ }^{*} 32 \%$ yield
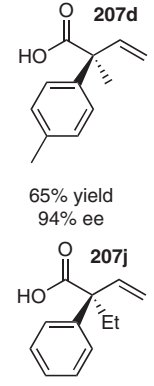

${ }^{*} 61 \%$ yield

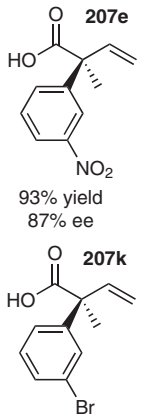

$69 \%$ yield

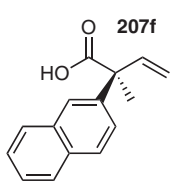

*66\% yield $92 \%$ ee

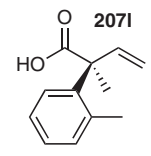

$0 \%$ yield

*Double the Ir and ligand loading was used.

Scheme 72 Branch selective Ir-AAA of trisubstituted electrophiles by an acyl anion equivalent nucleophile

$$
\overbrace{\overline{\mathrm{Ph}}}^{\mathrm{OCO}_{2} \mathrm{Me}}+{ }_{\mathrm{Ph}}^{\mathrm{OTBS}}
$$

2081.0 equiv

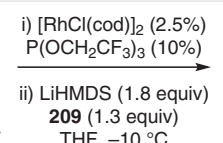
$209(1.3$ equiv)

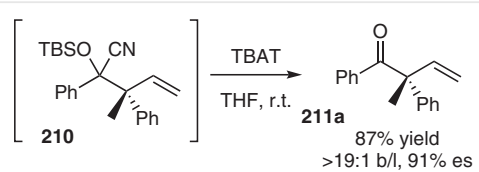

Scheme 73 Regio- and enantiospecific Rh-allylic alkylation of tertiary allylic carbonates with a cyanohydrin acyl anion equivalent

tron deficiency of the ligand facilitated a more rapid intermolecular alkylation event relative to $\pi-\sigma-\pi$ equilibration. Additionally, more bulky ligands resulted in significantly diminished enantiospecificity, presumably due to high coordinative unsaturation of the Rh complex, thus favoring the $\eta^{1}$-allyl species necessary for isomerization.
The reaction scope revealed high regioselectivity in all cases (Scheme 74). The stereospecificity of the reaction was high for most substrates, although disubstituted aromatics for $\mathrm{Ar}^{1}$ resulted in diminished enantiospecificity. The electronics of $\mathrm{Ar}^{2}$ showed high stereospecificity for electronwithdrawing substituents at the 4-position, and diminished specificity for electron-donating groups. This likely results from a more electrophilic $\pi$-allyl species with electron-

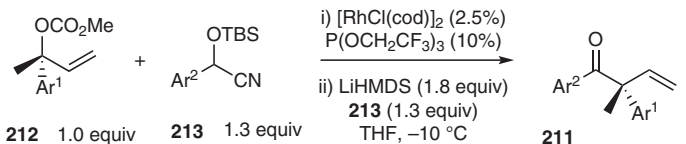

$$
\begin{aligned}
& \text { iii) TBAT, THF, r.t. }
\end{aligned}
$$

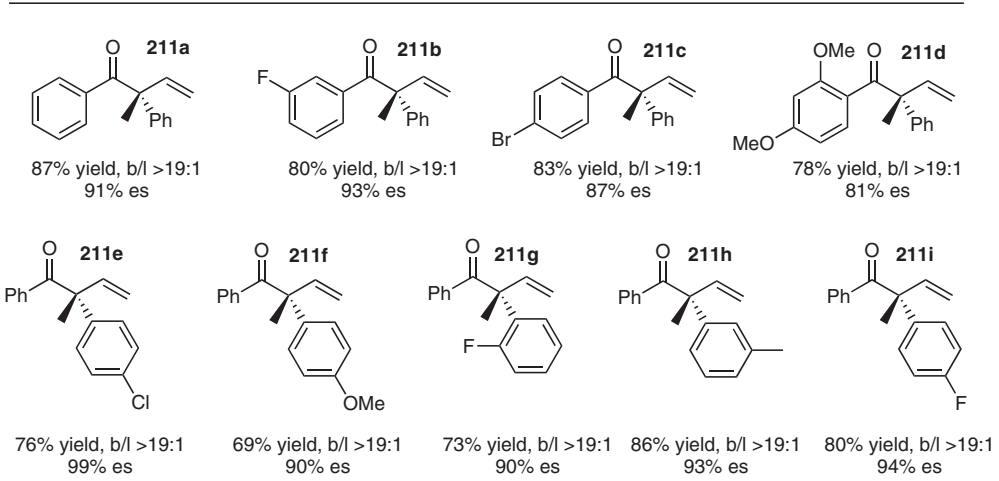

Scheme 74 Scope of Rh-allylic alkylation of tertiary allylic carbonates with a cyanohydrin acyl anion equivalent 
withdrawing substituents, favoring a rapid intermolecular reaction with cyanohydrin nucleophile relative to isomerization.

This work was extended to vinyl acyl anion equivalent $\mathbf{2 1 5}$ (Scheme 75). ${ }^{69}$ The product $\mathbf{2 1 7}$ can be chemoselectively reduced to afford the formal product from an aliphatic acyl anion equivalent addition, affording acyclic $\alpha$-quaternary $\alpha$-vinyl ketone $\mathbf{2 1 8}$. This reaction was highlighted for a tertiary allylic carbonate bearing two aliphatic substituents, with the reaction proceeding with high regio- and stereospecificity.

The Evans group demonstrated the first direct asymmetric alkylation reaction of $\alpha$-tertiary nitriles 219 by Rhcatalyzed AAA (Scheme 76). ${ }^{70}$ The process improves stepeconomy in the $\alpha$-functionalization of nitriles by generating the reactive anion in situ, thus side-stepping the synthesis and isolation of racemic $\mathrm{N}$-silylketenimines. The reaction was shown to proceed smoothly in the absence of additives; however, improved enantioselectivity was observed in the presence of a crown ether. High enantioselectivity was demonstrated for substrates bearing methyl, isopropyl, and benzyl substituents.
Additionally, the Evans group have shown a direct intermolecular Rh-catalyzed allylic alkylation of $\alpha$-aryl aldehydes (Scheme 77). ${ }^{71}$ Deprotonation with lithium hexamethyldisilazanide affords lithium enolates that undergo allylic alkylation with allyl benzoate (222) with high enantioselectivity. Although the reaction requires a ligand loading of 40 mol\%, ligand $\mathbf{L 2 5}$ is conveniently accessed in one step from BINOL.

Strangely, control experiments showed that both enolate isomers converge to the same enantiomer of product (Scheme 78). The respective silyl enol ethers are converted into the lithium enolates by treatment with methyllithium. The enantioselectivity in the catalytic reaction is significantly higher. It is worth noting that the presence of hexamethyldisilazanide is absent in the control experiments. The fact that both enolate isomers converge to the same product is all the more surprising considering the small steric differences between the $\alpha$-substituents for products 223b, 223c, 223d, 223h, 223i, 223j. It could be envisioned that there is electronic differentiation due to the strong dependence of enantioselectivity on the 4-substitution of the aromatic substituent.
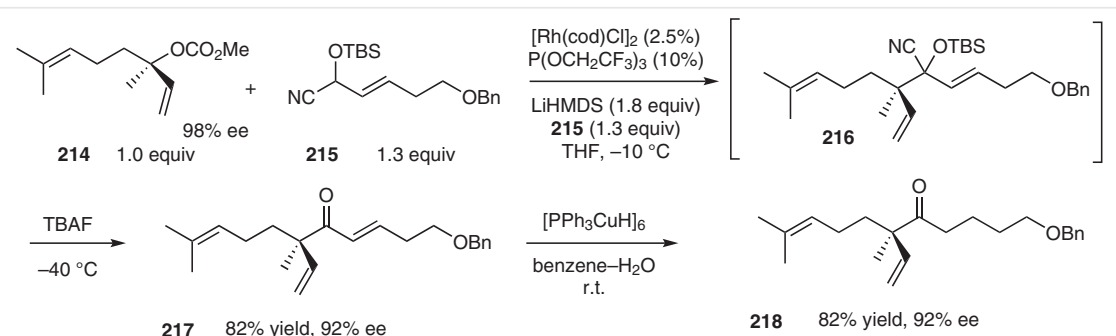

Scheme 75 Rh-allylic alkylation of tertiary allylic carbonates with a vinyl cyanohydrin acyl anion equivalent

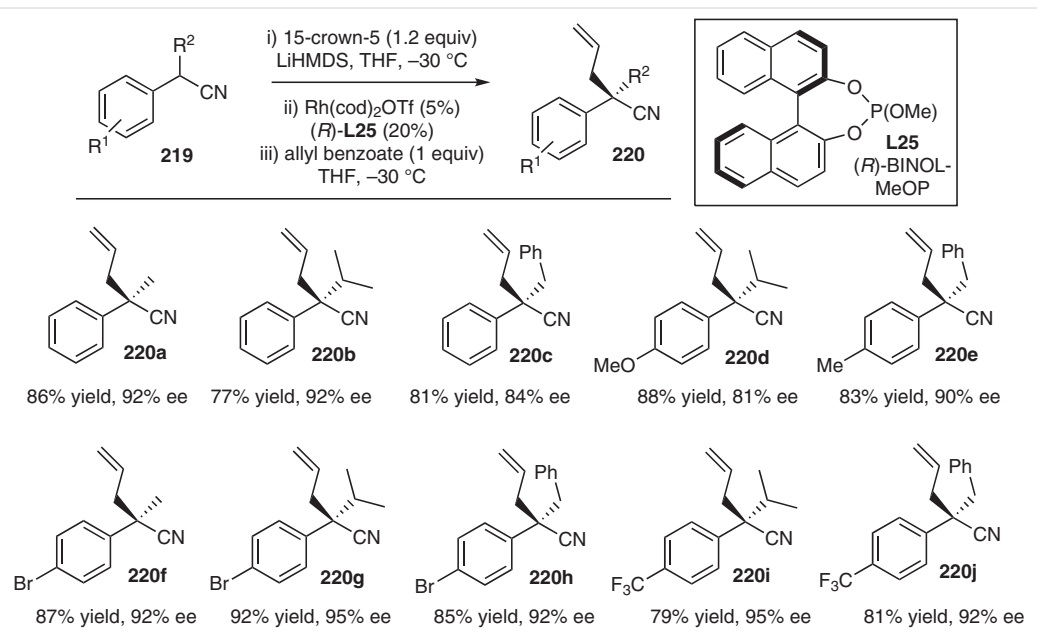

Scheme 76 Rh-catalyzed asymmetric alkylation of secondary benzylic nitriles 

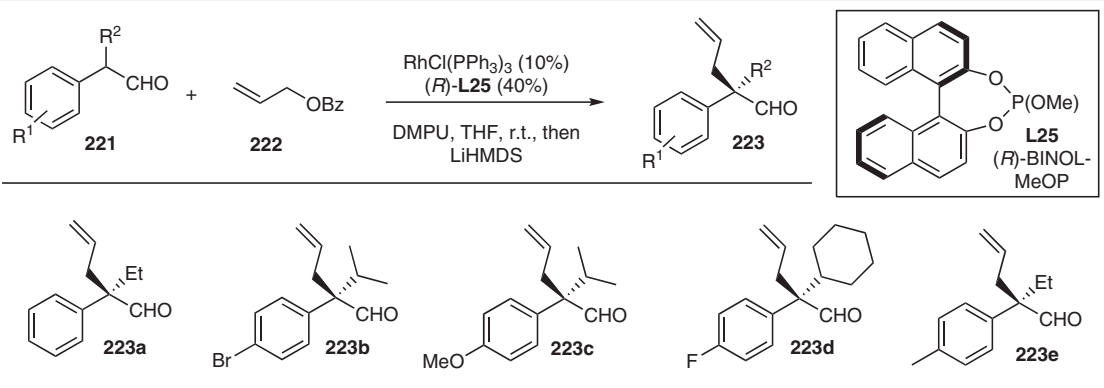

$74 \%$ yield, $92 \%$ ee

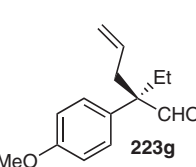

$66 \%$ yield, $94 \%$ ee

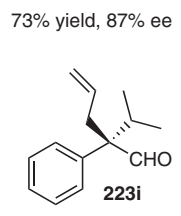

$64 \%$ yield, $92 \%$ ee
$75 \%$ yield, $92 \%$ ee

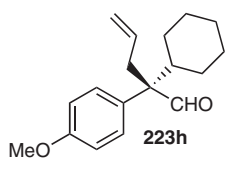

$61 \%$ yield, $90 \%$ ee

$83 \%$ yield, $77 \%$ ee

$79 \%$ yield, $91 \%$ ee

Scheme 77 Rh-catalyzed asymmetric allylic alkylation of $\alpha$-aryl aldehydes<smiles>CCC(C=O)c1ccc(OC)cc1</smiles>

2219

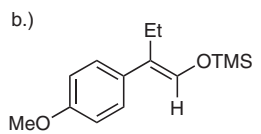

$224 E / Z 94: 6$

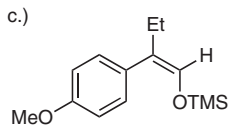

$225 E / Z 7: 93$
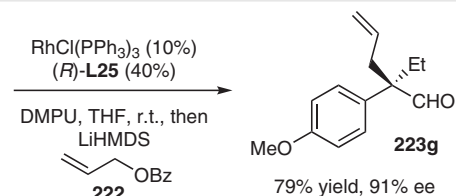

i) $\mathrm{MeLi}, \mathrm{THF}, 0{ }^{\circ} \mathrm{C}$
ii) $\mathrm{RhCl}\left(\mathrm{PPh}_{3}\right)_{3}(10 \%)$
$(R)-\mathrm{L} 25(40 \%)$
$\stackrel{\mathrm{DMPU}, \mathrm{THF}, \text { r.t. }}{\longrightarrow}$ $222 \mathrm{OBz}$

$$
\begin{aligned}
& \text { i) } \mathrm{MeLi}, \mathrm{THF}, 0{ }^{\circ} \mathrm{C} \\
& \text { ii) } \mathrm{RhCl}\left(\mathrm{PPh}_{3}\right)_{3}(10 \%) \\
& (R)-\mathrm{L25}(40 \%)
\end{aligned}
$$

Scheme 78 Effect of enolate geometry on stereochemical outcome

\section{Conclusions and Outlook}

An understanding of the mechanistic features of PdAAA has allowed for a variety of methods for the asymmetric synthesis of acyclic tetrasubstituted stereocenters including tertiary alcohols and ethers, $\alpha$-tertiary amines, and all-carbon quaternary carbons. Isoprene monoepoxide and related electrophiles have served as excellent precursors for forming difficult stereocenters, many of which appear in natural products. Additionally, the presence of hydroxymethylene and vinyl functional group handles in the resulting products allow for the synthesis of highly valuable sources of chirality. Stereocontrol on other electrophiles has been demonstrated in the branch-selective reverse-prenylation of oxindoles. This remains an exciting precedent in control of acyclic tetrasubstituted stereocenters on electrophiles; however, reactions with other nucleophiles is still underdeveloped in this area of research.

Despite the difficulty of achieving asymmetric induction on nucleophiles in Pd-AAA, important advances have been made over the past 20 years. The ability to control acyclic geometric elements of enol carbonates has been achieved by many well-designed substrate syntheses. This strategy works well in conjunction with strategies employing cyclic precursor such as azlactones, as evidenced by methods for the synthesis of tertiary alcohols, $\alpha$-tertiary amines, and all-carbon quaternary stereocenters. The addition of dual and triple catalysis has enabled the chemist to introduce new modes of stereocontrol as well as the ability to exploit multiple chiral catalysts within the same reaction for enhanced stereoselectivity.

Following the success of Pd- and Mo-AAA strategies for stereocontrol in the synthesis of acyclic stereocenters, recent advances in Ir- and Rh-AAA nicely demonstrate acyclic stereocontrol on both nucleophilic and electrophilic reaction partners. Undoubtedly, more efficient strategies in this broad area of research will continue to emerge, further enriching the options of synthetic chemists for stereocontrol in asymmetric synthesis.

\section{Funding Information}

Funding was provided in part by the Tamaki Foundation.

\section{Acknowledgment}

Dr. Yu Bai is thanked for reviewing the manuscript. 


\section{References}

(1) (a) Trost, B. M.; Van Vranken, D. L. Chem. Rev. 1996, 96, 395. (b) Trost, B. M.; Crawley, M. L. Chem. Rev. 2003, 103, 2921. (c) Trost, B. M. J. Org. Chem. 2004, 69, 5813. (d) Trost, B. M.; Machacek, M. R.; Aponick, A. Acc. Chem. Res. 2006, 39, 747. (e) Trost, B. M.; Fandrick, D. R. Aldrichimica Acta 2007, 40, 59.

(2) Although the term quaternary stereocenter is sometimes used interchangeably with tetrasubstituted stereocenter, for the sake of this review, quaternary stereocenters will only be applied to all-carbon quaternary stereocenters.

(3) Trost, B. M.; Jiang, C. J. Am. Chem. Soc. 2001, 123, 12907.

(4) Trost, B. M.; McEachern, E. J.; Toste, F. D. J. Am. Chem. Soc. 1998, $120,12702$.

(5) Trost, B. M.; McEachern, E. J. J. Am. Chem. Soc. 1999, 121, 8649.

(6) Trost, B. M.; Jiang, C.; Hammer, K. Synthesis 2005, 3335.

(7) Trost, B. M.; Bunt, R. C.; Lemoine, R.; Calkins, T. L. J. Am. Chem. Soc. 2000, 122, 5968.

(8) Trost, B. M.; Calkins, T. L.; Oertelt, C.; Zambrano, J. Tetrahedron Lett. 1998, 39, 1713.

(9) The $\pi$-allyl complex that places the higher priority group cis to the central hydrogen is denoted as the syn isomer

(10) Trost, B. M.; Toste, F. D. J. Am. Chem. Soc. 1999, 121, 4545.

(11) Feng, J.; Holmes, M.; Krische, M. J. Chem. Rev. 2017, For a review on metal-catalyzed synthesis of acyclic quaternary stereocenters: $117,12564$.

(12) For a review on diversity-oriented synthesis: Galloway, W. R. J. D.; Isidro-Llobet, A.; Spring, D. R. Nat. Commun. 2010, 1, 80; DOI: $10.1038 /$ ncomms1081.

(13) Du, D.; Li, L.; Xie, Z. Angew. Chem. Int. Ed. 2009, 48, 7853.

(14) Trost, B. M.; Dong, G.; Vance, J. A. Chem.-Eur. J. 2010, 16, 6265.

(15) Fagnou, K.; Lautens, M. Angew. Chem. Int. Ed. 2002, 41, 26.

(16) Trost, B. M.; Andersen, N. G. J. Am. Chem. Soc. 2002, 124, 14320.

(17) Trost, B. M.; Tang, W.; Schulte, J. L. Org. Lett. 2000, 2, 4013.

(18) Mandal, A. K.; Schneekloth, J. S.; Crews, C. M. Org. Lett. 2005, 7, 3645.

(19) Zeng, M.; Murphy, S. K.; Herzon, S. B. J. Am. Chem. Soc. 2017, 139, 16377.

(20) Trost, B. M.; Malhotra, S.; Chan, W. H. J. Am. Chem. Soc. 2011, $133,7328$.

(21) Zhang, P.; Le, H.; Kyne, R. E.; Morken, J. P. J. Am. Chem. Soc. 2011, $133,9716$.

(22) Ardolino, M. J.; Morken, J. P. Tetrahedron 2015, 71, 6409.

(23) Hou, X.-L.; Sun, N. Org. Lett. 2004, 6, 4399.

(24) (a) Trost, B. M.; Toste, F. D. J. Am. Chem. Soc. 1999, 121, 3543. (b) Trost, B. M.; Toste, F. D. J. Am. Chem. Soc. 2003, 125, 3090.

(25) Sawamura, M.; Nagata, H.; Sakamoto, H.; Ito, Y.J. Am. Chem. Soc. 1992, 114, 2586.

(26) Sawamura, M.; Nakayama, Y.; Tang, W.-M.; Ito, Y. J. Org. Chem. 1996, 61, 9090.

(27) Sawamura, M.; Sudoh, M.; Ito, Y. J. Am. Chem. Soc. 1996, 118, 3309.

(28) Mizuho, Y.; Kasuga, N.; Komiya, S. Chem. Lett. 1991, 2127.

(29) Sawamura, M.; Hamashima, H.; Ito, Y. J. Am. Chem. Soc. 1992, $114,8295$.

(30) Kuwano, R.; Ito, Y. J. Am. Chem. Soc. 1999, 121, 3236.

(31) Kuwano, R.; Nishio, R.; Ito, Y. Org. Lett. 1999, 1, 837.

(32) Kuwano, R.; Uchida, K.; Ito, Y. Org. Lett. 2003, 5, 2177.

(33) Zhang, K.; Peng, Q.; Hou, X.-L.; Wu, Y.-D. Angew. Chem. Int. Ed. 2008, $47,1741$.

(34) Jiang, G.; List, B. Angew. Chem. Int. Ed. 2011, 50, 9471.

(35) Ohmatsu, K.; Ito, M.; Kurieda, T.; Ooi, T. Nat. Chem. 2012, 4, 473.
(36) Fujita, T.; Yamamoto, T.; Morita, Y.; Chen, H.; Shimizu, Y.; Kanai, M. J. Am. Chem. Soc. 2018, 140, 5899.

(37) Belanger, E.; Houze, C.; Guimond, N.; Cantin, K.; Paquin, J.-F. Chem. Commun. 2008, 3251.

(38) Wang, W.; Shen, H.; Wan, X.-L.; Chen, Q.-Y.; Guo, Y.J. Org. Chem. 2014, 79, 6347.

(39) Weaver, J. D.; Recio, A. III.; Grenning, A. J.; Tunge, J. A. Chem. Rev. 2011, 111, 1846.

(40) Keith, J. A.; Behenna, D. C.; Sherden, N.; Mohr, J. T.; Ma, S.; Marinescu, S. C.; Nielsen, R. J.; Oxgaard, J.; Stoltz, B. M.; Goddard, W. A. J. Am. Chem. Soc. 2012, 134, 19050.

(41) Trost, B. M.; Xu, J.; Schmidt, T. J. Am. Chem. Soc. 2009, 131, 18343.

(42) Trost, B. M.; Xu, J.; Reichle, M. J. Am. Chem. Soc. 2007, 129, 282.

(43) Ariyarathna, J.; Tunge, J. A. Org. Biomol. Chem. 2014, 12, 8386.

(44) Minko, Y.; Pasco, M.; Lercher, L.; Botoshansky, M.; Marek, I. Nature (London) 2012, 490, 522.

(45) Starkov, P.; Moore, J. T.; Duquette, D. C.; Stoltz, B. M.; Marek, I. J. Am. Chem. Soc. 2017, 139, 9615.

(46) Alexy, E. J.; Zhang, H.; Stoltz, B. M. J. Am. Chem. Soc. 2018, 140, 10109.

(47) (a) Li, B. X.; Le, D. N.; Mack, K. A.; McClory, A.; Lim, N.-K.; Cravillion, T.; Savage, S.; Han, C.; Collum, D. B.; Zhang, H.; Gosselin, F. J. Am. Chem. Soc. 2017, 139, 10777. (b) Mack, K. A.; McClory, A.; Zhang, H.; Gosselin, F.; Collum, D. B. J. Am. Chem. Soc. 2017, 139, 12182.

(48) Kuwano, R.; Naoki, I.; Murakami, M. Chem. Commun. 2005, 3951.

(49) Maki, K.; Kanai, M.; Shibasaki, M. Tetrahedron 2007, 63, 4250.

(50) (a) Trost, B. M.; Ariza, X. J. Am. Chem. Soc. 1999, 121, 10727. (b) Trost, B. M.; Ariza, X. Angew. Chem., Int. Ed. Engl. 1997, 36, 2635.

(51) (a) Trost, B. M.; Czabaniuk, L. C. J. Am. Chem. Soc. 2012, 134, 5778. (b) Trost, B. M.; Czabaniuk, L. C. Chem.-Eur. J. 2013, 19, 15210.

(52) Trost, B. M.; Lee, C. B. J. Am. Chem. Soc. 1998, 120, 6818.

(53) Seto, M.; Roizen, J. L.; Stoltz, B. M. Angew. Chem. Int. Ed. 2008, 47, 6873.

(54) Estipona, B. I.; Pritchett, B. P.; Craig, R. A.; Stoltz, B. M. Tetrahedron 2016, 72, 3707.

(55) Behenna, D. C.; Liu, Y.; Yurino, T.; Kim, J.; White, D. E.; Virgil, S. C.; Stoltz, B. M. Nat. Chem. 2012, 4, 130.

(56) Numajiri, Y.; Jiménez-Osés, G.; Wang, B.; Houk, K. N.; Stoltz, B. M. Org. Lett. 2015, 17, 1082.

(57) Alexy, E. J.; Virgil, S. C.; Bartberger, M. D.; Stoltz, B. M. Org. Lett. 2017, 19, 5007.

(58) Hartwig, J. F.; Stanley, L. Copper-Catalyzed Allylic Substitution, In Organotransition Metal Chemistry: From Bonding to Catalysis; Hartwig, J. F., Ed.; University Science Books: Mill Valley, 2010, 999-1008.

(59) Trost, B. M.; Dogra, K. J. Am. Chem. Soc. 2002, 124, 7256.

(60) (a) Trost, B. M.; Zhang, Y. J. Am. Chem. Soc. 2006, 128, 4590. (b) Trost, B. M.; Zhang, Y. J. Am. Chem. Soc. 2007, 129, 14548.

(61) Trost, B. M.; Dogra, K.; Franzini, M. J. Am. Chem. Soc. 2004, 126, 1944.

(62) Trost, B. M.; Miller, J. R.; Hoffman, C. M. Jr. J. Am. Chem. Soc. 2011, 133, 8165.

(63) Kanayama, T.; Yoshida, D.; Miyabe, H.; Takemoto, K. Angew. Chem. Int. Ed. 2003, 42, 2054.

(64) Hethcox, J. C.; Shockley, S. E.; Stoltz, B. M. ACS Catal. 2016, 6, 6207.

(65) Krautwald, S.; Sarlah, D.; Schafroth, M. A.; Carreira, E. M. Science (Washington, D. C.) 2013, 340, 1065. 
(66) Shockley, S. E.; Hethcox, J. C.; Stoltz, B. M. Angew. Chem. Int. Ed. 2017, 56, 11545.

(67) Evans, P. A.; Oliver, S.; Chae, J. J. Am. Chem. Soc. 2012, 134, 19314.

(68) Evans, P. A.; Oliver, S. Org. Lett. 2013, 15, 5626.
(69) Turnbull, B. W. H.; Oliver, S.; Evans, P. A. J. Am. Chem. Soc. 2015, $137,15374$.

(70) Turnbull, B. W. H.; Evans, P. A. J. Am. Chem. Soc. 2015, 137, 6156.

(71) Wright, T. B.; Evans, P. A. J. Am. Chem. Soc. 2016, 138, 15303. 